\title{
Utopía y profetismo desde América Latina
}

\section{Un ensayo concreto de soteriología histórica.}

\author{
Ignacio Ellacuria, \\ Centro de Reflexión Teológica, \\ San Salvador, El Salvador.
}

Utopia y profetismo, si se presentan por separado, tienden a perder su efectividad histórica y propenden a convertirse en escapismo idealista, con lo que, en vez de constituirse como fuerzas renovadoras y liberadoras, quedan reducidas, en el mejor de los casos, a funcionar como consuelo subjetivo de los individuos o de los pueblos.

No es ese el caso en las manifestaciones clásicas del profetismo y de las grandes preocupaciones utópicas. Desde luego, no es así en la Biblia, pero tampoco en otros acontecimientos significativos de la historia de la salvación. Con wodo ha de reconocerse un peligro real, en el que se cae repetidamente, de separarlas, de desencarnar tanto la utopía como la profecía, sea por reduccionismo subjetivista o por reduccionismo transcendentalista, leyéndolas en clave intemporal de eternidad, cuando la eternidad cristiana está vinculada inexorablemente a la temporalidad, una vez que el Verbo se hizo historia.

Pero para lograr la conjunción adecuada de utopía y profecía es menester situarse en el lugar histórico adecuado. Toda conjunción de esas dos dimensiones humanas e históricas, para ser realista y fccunda, nccesita "situarse" en precisas coordenadas geo-socio-temporales. De lo contrario desaparece el impulso insoslayable del principio de realidad, sin el que ambas son juego mental, más formal que real. Pero hay unos lugares históricos más propicios al surgimiento de ulopistas proféticos, de profelas utópicos. Se dice que en las culturas envejecidas ya no hay lugar para el profclismo y la utopía, sino para el pragmatismo y el egoísmo, para la verificación contable de los resultados, para el cálculo cienúfico de insumos y resultados; en el mejor de los casos para la institucionalización, legalización y ritualización del espíritu que renueva lodas las cosas. Sea o no inevitable esta situación, quedan, sin embargo, lugares donde la esperanza no es, 
sin más, la sumatoria cínica de cálculos infinilesimales, sino el de esperar y "esperanzar" contra todo juicio dogmático, que cierra el futuro del proyecto y de la lucha.

Uno de esos lugares es América Latina - para sospecharlo previamente, ya se volverá sobre ello, baste con citar hechos como los movimientos revolucionarios o la teologla de la liberación-, desde donde pueden historizarse mejor no solo las relaciones teóricas entre utopía y profecía, sino también para trazar los rasgos generales de un futuro utópico de alcance universal mediante el ejercicio concreto de un profelismo histórico.

Pensar que la utopía en su propia formalidad intrínseca es algo fuera de todo lugar y tiempo histórico, supone subrayar una de las características de la utopía con descuido de lo que es su naturaleza real, tal como se ha dado en quienes de una u otra forma han sido utopistas. No hay posibilidad de salirse de la hisloricidad de lugar y tiempo, aunque tampoco es inevitable quedarse encerrado en los límites de este lugar y de este tiempo. Tampoco es cierto que la mejor forma de universalizar la profecía y el utopismo sea el intentar salirse o prescindir de todo condicionamiento limitante. Profecía y utopía son en sí mismas dialécticas. La profecía es pasado, presente y futuro, aunque es sobre todo presente de cara al futuro, es futuro de cara al presente. La ulopía es historia y metahistoria, aunque es sobre todo metahistoria, nacida sin embargo de la historia y remitente inexorablemente a ella, sea a modo de huída o a modo de realización. De ahí la necesidad de poner bien los pies en una tierra determinada para no perder fuerza, como le pasaba a Anteo cuando lo mantenían en el aire.

Es lo que se pretende hacer en este trabajo, mediante la puesta en marcha, desde el contexto histórico de América Latina, del proletismo como método y de la utopía como horizonte. Todo ello desde una perspectiva explícitamente cristiana tanto en lo que se refiere a la profecía como en lo que se refiere a la utopía.

1. La utopía cristiana sólo puede ser construida desde el profetismo y el profetismo cristiano debe tomar en cuenta la necesidad y las caracteristicas de la utopia cristiana.

No se conoce de antemano y menos a priori cuál puede ser la concreción histórica de la utopía cristiana, y solo una utopía cristiana concreta cs operativa para la historización del reino de Dios. Esla afirmación global incluye un conjunto de afirmaciones, cuya discusión no la vamos a hacer previamente, pues será el desarrollo del trabajo, el que explicará su sentido y justificación. Tales afirmaciones son: (a) hay una utopía cristiana general e indelinida, (b) esa utopia general debe concretizarse en términos histórico-sociales, (c) esa utopía esর́ en relación con el reino de Dios, (d) el reino de Dios debe hislorizarse y (e) el reino de Dios se operativiza mediante la puesta en marcha de una utopia concreta. 
Ciertamente la ulopía cristiana, nacida de la revelación, de la tradición y aun del magisterio, tiene ciertas notas, sin las cuales no puede cualificarse como cristiana. Una utopía, que pretenda ser cristiana no puede dejar a un lado el profetismo del Antiguo Testamento (profetas y no profetas), el sermón de la montaña, el discurso de la última cena, el Apocalipsis, la comunidad primitiva, los padres de la Iglesia, los grandes santos, algunos documentos conciliares y pontificios, por citar algunas fuentes a modo de ejemplo. Pero la imporancia de unas u otas nolas, la conjunción de ellas para formar un todo, su realización his de modo que el cierre de la misma debe hacerse por medio de una opción, en definitiva de una opción del pueblo de Dios con su carácter orgánico antes que jerárquico (Rom 12, 4-8; 1Cor 12, 4-31), en el que caben muchos carismas, funciones y actividades, unos más pertinentes que ouros a la hora de definir los caracteres históricos conslatables de la utopía cristiana.

Esla utopía, que puede llamarse general y universal, porque contiene unos mínimos que no pueden faltar, al menos en la intención y en el proyecto y porque apunta a un futuro universal, cuya culminación es escalológica, debe concretarse precisamente para lograr que se vaya aproximando el reino de Dios. Hasta cieno punto pueden equipararse utopía cristiana y reino de Dios, aunque cuando.se habla de aquélla se acentúa el carácter utópico de éste y no otras notas suyas. Pero la concreción de la ulopía es lo que va historizando el reino de Dios tanto en el corazón del hombre como en las estructuras, sin las que ese corazón no puede vivir. No es hora de desarrollar aquí la idea muy trabajada por la teología de la liberación de que debe procurarse una historización del reino tanto en lo personal como en lo societal y en lo político. Aunque la teología de la liberación lo ha hecho a su modo, toda la tradición de la Iglesia lo ha procurado siempre. Si se lee, por ejemplo, la Gaudium et spes o las distintas enciclicas papales de la enseffanza social de la Iglesia, se verá la necesidad de historizar, si no el reino, al menos la fe y el mensaje cristiano. Que esto se haga con mayor o menor vigor profético y utópico, no obsta para que deje de verse la necesidad de hacerlo.

La pregunta, entonces, es cómo lograr mejor esa concreción, aceptando el supuesto fundamental de que la utopla general y universal ya está anunciada y prometida, de modo que su concreción no sólo no puede negarla o sobrepasarla, sino que debe vivir de ella, aunque creativamente, porque el mismo Espíritu, que la fue animando en sus anteriores y fundantes dinamismos, sigue posibilitanto nuevos dinamismos. La respuesta apunta al profetismo cristiano. El profetismo, recta y complejamente entendido, está en el origen de la utopía universal y general; ese mismo profetismo es el que se necesita para la concreción de la utopia Un profetismo que necesitará ayuda de otras inslancias - por ejemplo, la del magisterio-, pero que no puede ser sustituido por ellas. Sin profetismo no hay posibilidad de hacer una concreción cristiana de la utopia y, consiguientemente, una realización histórica del reino de Dios. Sin un ejercicio intenso y 
auténtico del profetismo cristiano no se puede llegar téricamente y, mucho menos, prácticamente, a la concreción de la utopía cristiana. Aquí tampoco la ley puede sustituir a la gracia, la instiución a la vida, lo ya establecido tradicionalmente a la novedad radical del Espiritu.

Aquí se entiende por profelismo la contrastación crítica del anuncio de la plenitud del reino de Dios con una siluación histórica determinada iEs posible esta contrastación? ¿No son dos cosas radicalmente distintas y que se mueven en planos diferentes, el reino de Dios y las realidades históricas con sus proyectos mundanos? La respuesta a esta objeción o pregunta, no por ser compleja, deja de ser clara: la plenitud del reino, sin identificarse con ningún proyecto personal o estructural ni con ningún proceso determinado, está en relación necesaria con ellos. No hay más que verlo en los planteamientos del Antiguo y del Nuevo Testamento. Podrá darse, según los casos, mayor importancia a lo transcendente que a lo acaeciente, a lo interior que a lo exterior, a lo intencional que a las realizaciones. Pero nunca puede faltar uno de los dos aspectos. El reino de Dios es, en definitiva, una historia transcendente o una transcendencia histórica en paralelo estricto con lo que es la vida y la persona de Jesús, pero de tal forma que es la historia la que lleva a la transcendencia, ciertamente porque la transcendencia de Dios se ha hecho historia, ya desde el inicio de la creación.

Esa plenitud del reino de Dios, la cual implica que se tenga en cuenta todo el reino de Dios y toda la proyección del reino de Dios, debe contrastarse con una determinada situación histórica. Si el reino, por ejemplo, anuncia la plenitud de la vida y el rechazo de la muerte y la sibuación histórica de los hombres y de las estructuras es el reino de la muerte y la negación de la vida, el contraste es manifiesto. La contrastación de un reino historizado pone de manifiesto las limitaciones (falta de divinización o de gracia) y, sobre todo, los males (pecados personales, sociales y estructurales) de una determinada situación histórica. Es asi como el profetismo, que se inicia con esta contrastación - supuesto eso sí aquella visión general del reino a la que se aludía antes y que de distintos modos la revelación de Dios ha ido haciendo llegar a la humanidad-, eslá en condiciones de prenunciar el futuro e ir hacia él. De este modo, que podría llamarse dialéctico, superando los límites y los males del presente, que son límites históri$\cos$, se va dibujando, a modo de superación, el futuro deseado, cada vez más acorde con las exigencias y los dinamismos del reino. A su vez, el futuro anunciado y esperado, como superación del presente, ayuda a ir superando esos Ilmites y esos males.

Concebido así el profetismo, se ve cuán necesario es para que la utopía no se convierta en una evasión abstracta del compromiso histórico. "La miseria religiosa es, por una parte, la expresión de la miseria real y, por la otra, la protesta contra la miseria real. La religión es el suspiro de la criatura oprimida, el corazón de un mundo sin corazón, así como es el espíitu de una situación carente de 
espiritu" (K. Marx, Contribución a la Crírica de la Filosofla del Derecho de Hegel, 1844). Pero, si es así, no tiene por qué convertirse en el opio del pueblo, como continúa diciendo el mismo texio marxiano. Si es más protesta que mera expresión, si es más lucha que mero desahogo, si no se queda en mero suspiro, si la protesta y contraste se convierten en utopía histórica, que niega el presente y lanza hacia el futuro, si, en definitiva, se entra en la acción profética, se hace historia en la línea de la negación y de la superación, y no en la línea de la evasión. Por la vía del profetismo, aunque la utopía no sea plenamente realizable en la historia, como es el caso de la utopía cristiana, no por eso deja de ser efectiva. Si no fuera de ningún modo realizable, correría el peligro casi insuperable de convertirse en opio evasivo, pero, si debe alcanzar un grado alto de realización y está puesta en relación estrecha con la contradicción profética, puede ser animadora de la acción correcta. Una utopía, que no sea de algún modo animadora y aun efectora de realizaciones históricas no es una utopía cristiana, ni siquiera es una visión ideal del reino, sino que es una visión idealista e ideologizada del mismo. Si, por ejemplo, no se tiende a que las armas se conviertan en arados, sino que se sueña evasivamente en ello, la utopia se desvanece y lejos de pugnar contra el armamentismo se convierte en desahogo bucólico para consumo de horas libres y ociosas. No es esta la intención ni la realidad de la utopía y del proletismo cristiano.

Pero si la utopia no puede ser realmente utopía cristiana sin el profetismo que la inspire, tampoco el profetismo será realmente cristiano sin la animación de la utopia. El profetismo cristiano vive de la utopía cristiana, la cual, en tanto que utopía vive más y se alimenta de la interpelación que hace el Espíritu a través de la historia, pero en tanto que cristiana vive más del anuncio y de la promesa explícila e implícilamente expresadas en la revelación ya dada. Un profetismo, que no uviera en cuenta el anuncio y la promesa ya dados, estaria mal preparado para la contradicción del mal y, sobre todo, completamente impreparado para construir un diseño histórico de algo que pretendiese responder a las exigencias concretas del reino de Dios, tal como éste ha sido anunciado desde antiguo, pero especialmente por parte del Jesús histórico.

La prioridad en la plenitud de la acción cristiana ha de ser atribuida a la revelación y a la promesa de Jesús, incluso en la fase destructiva del profelismo. Esto es todavía más válido, cuando lo que se busca es realizar la voluntad o los designios de Dios para cuyo discernimiento es indispensable tanto el Espíritu de Cristo como los trazos históricos de la marcha por la historia de Jesús de Nazaret. Casi parece tautológico e innecesario decir que el carácter cristiano de la utopía no puede ser dado a plenitud más que desde la fe cristiana, explícilamente aceptada y vivida, aunque sin desconocer tampoco que el Espiritu puede valerse de cristianos no explícilamente tales y aun de anticristianos, como en el caso de Caifás, para anunciar y realizar algunos rasgos fundamentales de la utopía cristiana. 
Sucede, sin embargo, que lo dado necesita actualizarse (en el sentido zubiriano del término). Actualizarlo no significa primariamente ponerlo al día, al menos en el sentido que esta expresión puede tener de estar a la moda de los tiempos. Actualizarlo significa, más bien, dar realidad actual a lo que formalmente es una posibilidad histórica y que, como al, puede ser tomada o dejada, leída de un modo o de otro. Lo que debe ser actualizado es, entonces, lo dado, pero la lectura e interpretación de lo dado, la opción por una parte u otra de lo dado, depende de un presente historico y de unos sujetos históricos. La actualización histórica de la utopía ya dada surge, ante lodo, de la interpelación (signos de los tiempos), que va dándose por el Espíritu en la hisloria. Pero los signos son históricos, aunque lo significado por ellos transcienda lo meramente hislórico. Para esa transcendencia tiene otra vez prioridad el Espíritu, pero en relación inseparable con las concreciones históricas. Esto que es válido para la interpretación lo es más aún para la realización.

Efectivamente, la ulopía tiene un cierto carácter de ideal irrealizable de una vez por todas, pero al mismo tiempo tiene el carácter de algo realizable asintóticamente en un proceso permanente de aproximación y, por tanto, implica mediaciones teóricas y prácticas, que se toman más de la dimensión categorial de la historia. Ciertamente se trata de una vlopía cristiana y, en ese sentido, mantiene muy explícitamente la dimensión transcendente del reino. Pero, incluso esta dimensión no puede formularse separada de lo categorial, aun en las formulaciones más estrictamente evangélicas. No se trata tan sólo ni primariamente de un problema de lenguaje -el reino como banquete, como campo de labores, etc.-, sino de algo más hondo, de la necesidad ineludible de hacer histórica la transcendencia del reino, lo cual es fácil de ver en las recomendaciones morales relacionadas con la vida cotidiana, pero que también se refiere a objetivaciones políticas y sociales -casos de soldados, de autoridades, de leyes, de costumbres sociales, etc.-, como ocurre no solo en todo el Antiguo, sino ambién en el Nuevo Tesiamento.

Por tanto, ha de mantenerse unitariamente que para dar con el carácter transcendente de lo categorial y para categorizar interpretativa y prácticamente lo transcente es necesaria la interpelación del Espiritu en la historia. A través de lo verdadero y de lo falso, de lo bueno y de lo malo, de lo justo y de lo injusto, etc., valorados unitariamente desde lo que es la fe como don recibido y práctica cotidiana, es como se capta la transcendencia de lo hisbrico y, a su vez, se proyecta y realiza transcendentemente algo que es unitariamente histórico y suprahistorico. El profetismo lo que recoge y expresa es esa interpelación historicotranscendente del Espíritu, que hace presente la utopía ya ofrecida y la contrasta con los signos de los tiempos. Así se alimentan mutuamente profetismo y utopía, hisloria y transcendencia Ambos son históricos y ambos son transcendentes, pero ninguno de ellos llega a ser lo que ha de ser si no es en relación con el otro. 


\section{América Latina es hoy un lugar privilegiado de profetismo} y utopía, aunque todavía la actualización de su potencialidad profética y utópica esté lejos de ser satisfactoria.

No es una afirmación voluntarista o arbitraria cl señalar a América Latina en el momento actual como lugar privilegiado de utopía y profetismo, sino que su propia realidad y algunas de sus realizaciones así lo demuestran.

Como realidad se trata de un continente con características peculiares, que lo asemejan a las atribuidas al siervo de Yahvé. En esta condición coincide con otras regiones del mundo, casi con la mayor parte de las regiones del mundo. Es una región maltratada ya desde la conquista armada hecha por la cristiandad española, que sin perder su corazón humano, tienc, sin cmbargo, su rostro desfigurado, casi irreconocible como humano, si no es en lo que tiene de dolor y de trágico (Is 52, 2-12); además, casi ha perdido su misma condición de pueblo (Os 1, 6-9; 1Pe 2, 10). Pero esa condición, que en gran parte la configura como realidad objetiva, tiene la de una concicncia muy activa de protesta y, más específicamente, una conciencia cristiana de liberación muy viva, todo lo cual lo sitúa en una excelente disposición para ejcrer un lucrte profecismo teórico y práctico, lo cual queda confirmado por lo mucho y significativo que ya ha logrado en este campo con sus mártires y profetas recientes, surgidos por todas partes y en todos los estratos del pueblo y de la Iglesia. América Latina es una región, en la cual contrasta su gran potencialidad y riqueza de recursos con el estado de miseria, injusticia, opresión y explotación, impucsto a una gran parte del pueblo, dándose con ello base objetiva para el contraste de la utopía, dada en su rica potencialidad, con el proletismio, pre-dado en la negación de la ulopía por la realidad cotidiana. Los incesantes movimientos revolucionarios en lo político y los movimientos cristianos en lo religioso son distintas formas de cómo una poderosa conciencia colectiva utópica y profética se ha hecho reflejo y cargo de lo que es la realidad objetiva.

Como realización, América Latina se debate fuera y dentro de la Iglesia en un intento poderoso por romper sus cadenas y por construir un futuro distinto, no sólo para sí misma, sino para toda la humanidad. La situación, padecida en su propia came, junto con su protesta efectiva, es una condena fehaciente del orden histórico mundial -y no sólo del orden económico-político internacional y, por negación, un anuncio de un orden distinto. La verdad real del ordenamiento histórico actual se refleja crudamente, no sólo ni principalmente en las franjas de miseria y, sobre todo, de degradación de los países ricos, sino en la realidad del tercer mundo, expresada conscientemente en la múltiple protesta de América Latina.

Esa verdad demuestra la imposibilidad de la reproducción y, sobre todo, de la ampliación significativa del orden histórico actual, y demuestra, más radicalmente aún, su indeseabilidad, por cuanto no es posible su universalización, 
sino que lleva consigo la perpetuación de una distribución injusta y depredatoria de los recursos mundiales y aun de los recursos propios de cada nación, en beneficio de unas pocas naciones. Esto hace que la América Latina profética y utopica no busque imilar a quienes hoy van por delante y se sitúan por encima, sino que busca en lo objetivo y en lo subjetivo un orden distinto, que permila una vida humana no sólo para unos pocos, sino para la mayor parte de la humanidad. El mundo desarrollado no es de ninguna manera la ulopía deseada, incluso como modo de superar la pobreza, cuanto menos la injusticia, sino el aviso de lo que no se debe ser y no se debe hacer.

Este movimiento histórico se refleja dentro de la Iglesia como algo cualitativamente nuevo. La opción preferencial por los pobres, entendida de modo radical y efectivo, de modo que éstos sean los que dinámicamente tomen la iniciativa, puede, ante todo, transformar a la Iglesia radicalmente y puede así constituirse en clave y motor de lo que ha de ser una utopía cristiana como proyecto histórico liberador. Tal movimiento se refleja ya en las distintas formas téricas y prácticas de la teología de la liberación, que es en sí misma un modo de profetismo eficaz para la animación de una nueva utopía histórica cristiana. Por ello se la teme tanto dentro y fuera de la Iglesia.

Pero el lugar privilegiado que es América Latina para el profetismo y la utopia no debe llevar a la ilusión de considerar que toda ella o toda la Iglesia latinoamericana están ejerciendo actualmente la misión profético-utópica. América Latina en su conjunto est́́ configurada por el mismo "pecado del mundo," que afecta al resto de la humanidad y en ella predominan las "estructuras de pecado," no sólo como sujeto pasivo, que las padece, sino como sujeto activo, que las produce. Los modos de realización de la pseudo utopía capitalista y, en mucho menor grado, de la pseudo utopía socialista predominan en la configuración de la sociedad y de los pueblos latinoamericanos. Tanto los modos económicos como sociales, políticos y culturales del capitalismo se reproducen y se agravan en América Latina por su condición de sociedades dependientes, que apenas tienen a donde enviar los efectos y residuos de su explotación, por lo que los dejan dentro de sus propias fronteras, cosa que tratan de evitar las naciones más poderosas. No se dan reformas del capitalismo en el subcontinente, aunque si han empezado a intentarse reformas del socialismo. Y en ninguna parte se vive la opción preferencial por los pobres, la superación del dinamismo del capital y de las exigencias del orden internacional, ni menos aún se ha encontrado la forma de que el sujeto primario de los procesos sea el pueblo dominado y oprimido. No es acertado echar la culpa de lodos los males latinoamericanos a los otros, porque tal exculpación legitima o encubre comportamientos y acciones del todo condenables, ya que los sistemas, los procesos, los dirigentes, no por ser dependientes, dejan de asurnir y aun de potenciar los males de su dependencia. 
Tampoco toda la Iglesia en América Latina, ni siquiera una gran parte de ella, está cumpliendo con su vocación de profetismo utópico. Por más escandaloso que esto resulte en una siluación como la latinoamericana - subcontienente donde conviven la injusticia y la fe-, gran parte de los cristianos, incluidos religiosos, sacerdotes, obispos, cardenales y nuncios, no sólo carecen del carisma profético, sino que lo contradicen y aun se constituyen en antisigno como perseguidores del profetismo y favorecedores de las estructuras y fuerzas de dominación, siempre que éstas no pongan en peligro las ventajas y los privilegios institucionales. Aunque la parte de la Iglesia que hace una tarea antiprofética y antiutópica no constituya mayoría en la institución eclesiástica, predomina el noprofelismo y aun la desconfianza contra toda forma de profelismo, al que se propende a confundir con la eliquela equivocada de magisterio paralelo. Si se elige como piedra de toque la opción preferencial por los pobres, se aprecia, después de largas luchas, un cierto respeto verbal, pero poca práclica efectiva por parte de la jerarquía. Si se toma como criterio la posición ante el movimiento de la teologia de la liberación, aunque se ha dado cierta mejora formal, sigue la desconfianza, cuando no más sutiles formas de ataque.

Pero, aunque se dan estos rasgos negativos, no puede desconocerse que, como se decía en párafos anteriores, se ha venido dando un florecimiento de la utopía y del profetismo en América Latina, que sitúan a su pueblo y, en algún modo, a su Iglesia en posición de vanguardia para definir cúl ha de ser su misión en el mundo actual, cosa que no puede verse ni desde un lugar abstracto, ni mucho menos desde un lugar encarnado en las estructuras del mundo dominanie.

\section{El profetismo utópico de América Latina apunta a una} nueva forma de libertad y humanidad mediante un proceso histórico de liberación.

La realidad misma de América Latina, sobre todo vista desde la fe cristiana, constituye una denuncia profética radical del orden internacional, tanto en su confrontación norte-sur como en su confrontación este-oeste, asi como de la actitud, comportamiento y expectativas, promovidas por las vanguardias culturales y los modelos propuestos como ideales de libertad y de humanidad.

El entrechoque de los intereses en los conflictos norte-sur, este-oeste hace que la mayoría de los países del mundo sean cada vez más dependientes y sistemáticamente empobrecidos, y, sobre todo, los introduce en un proceso de pérdida de identidad por el arastre hacia una imitación, que reluerza la dependencia y aun la esclavitud. No se niega que en los países capitalistas y socialistas avanzados se den valiosos principios teóricos y prácticos, que pueden y deben ser asumidos crílica y creativamente por los demás países, de modo que un puro regreso a un supuesto primitivismo es imposible y está sujeto a múltiples formas de dependencia; más aún es imposible salirse de la única historia real de 
interdependencia, en la que forzosamente han de desempeñarse lodos los pueblos. Pero la forma imperialista como se dan las relaciones norle-sur, esteoeste debe ser repudiada por el bien de los paises que la sufren y por el bien de los paises que la imponen.

Esta es una denuncia muy claramente expuesta por la tcoría de la dependencia y, luego, por la teología de la liberación, y que ha sido recogida finalmente de un modo profético por Juan Pablo II en la Solicitudo rei socialis, en seguimiento de la Populorum Progressio de Pablo VI y de la Gaudium et spes del Vaticano II: "Cada uno de los bloques lleva oculta intemamente, a su manera, la tendencia al imperialismo, como se dice comúnmente, o a formas de neocolonialismo; tentación nada fácil, en la que se cae muchas veces, como enseffa la historia, incluso reciente" (SRS, 22).

Un Tenómeno tan dramálico como el de la deuda externa de América Latina, tanto en su origen como en el modo de exigir su pago, es uno de los síntomas más claros de lo injusio de la relación y del daño morlal, que se hace a los pucblos, a los que se supone se quiere ayudar (L. de Sebastián, La deuda externa de América Latina y la banca insernacional, San Salvador, 1987). Ya en general puede decirse que el tipo de relación de los poderosos con los menos fuertes está llevando a que unos pocos (países o grupos sociales) sean más ricos, mientras que las mayorías son más pobres, agrandándose y agravándose la brecha entre unos y otros. Pero, en el caso de la deuda externa, se aprecia en concreto cómo los préstamos, que originaron la deuda, se hicieron con frecuencia de forma leonina y con la complicidad de gobiemos y clases sociales, no populares sin provecho alguno para las mayorias. El reclamo de la deuda, en cambio, pesa muy particularmente sobre los pueblos, a los que se les priva de la posibilidad de salir de su pobreza a través de un desarrollo armónico y mira mucho más por el interés del capital que por las exigencias del trabajo, contradiciendo así un principio básico de humanidad (prioridad del trabajo sobre el capital) y un principio básico de la fe cristiana (prioridad de los muchos pobres sobre los pocos ricos). Aparece asi el mundo regido por la insolidaridad y la falta de misericordia y cuidado de los demás, de modo que aparece configurado y conformado antievangélicamente por la injuslicia, con lo cual se presenta como la palmaria y constatable negación del reino de Dios anunciado por Jesús.

En particular, la situación real de América Latina denuncia proféticamente la malicia intrínseca del sistema capitalista y la mentira ideológica de la apariencia de democracia, que lo acompana, legitima y encubre.

Suele preguntarse por qué el profetismo latinoamericano no denuncia las formas socialistas político-económicas y propende a diseñar utopías de corte anti-capitalista. La razón está en que el profetismo se aplica sobre los males presentes y éstos, en su mayor parte, se deben a formas capitalistas de dominación. Los males de los sistemas socialistas, tanto en lo económico como en 
lo político, se hacen presentes en situaciones como las de Cuba, Nicaragua y en algunos movimientos revolucionarios. Pero, excluidos casos extremos como el de Sendero Luminoso en Peni, los males de los sistemas socialistas no tienen comparación con la prolongación, extensión y gravedad de los del sistema capitalista en América Latina, por lo que el profetismo histórico se da más en la dirección del rechazo del capitalismo que del socialismo.

La Iglesia, antes más inclinada a condenar el socialismo que el capitalismo y más dispuesta a ver en éste defectos corregibles y en aquél males intrínsecos surgidos de su propia esencia histórica, hoy tiende a situar ambos sistemas en pie de igualdad al menos. "Como es sabido, la tensión entre el Este y el Oeste no refleja de suyo una oposición entre diversos grados de desarrollo, sino más bien entre dos concepciones del desarrollo humano, de al modo imperfectas que exigen una corrección radical... La doctrina social de la Iglesia asume una aclitud critica tanto ante el capitalismo liberal como ante el colectivismo marxista" (SRS, 21). Pero el profetismo local debe centrarse, por su propia naturaleza, en la negación de lo que es de hecho el causante de los males, que afectan a una determinada realidad.

Por to que toca al capitalismo especialmente, su malicia intrínseca, una vez pasada su etapa de explotación despiadada en los parses occidentales, lo cual permitió la primera acumulación, sólo se observa en toda su magnitud fuera de las fronteras de los países ricos, que exportan de múltiples formas los males del capitalismo a la periferia explocada. No se trata tan sólo del problema de la deuda externa ni de la explotación de las materias primas o de la búsqueda de lugares tercermundistas para colocar los desechos de toda indole, que producen los países más desarrollados, sino, sobre todo, de un arrastre casi irresistible hacia una profunda deshumanización, inserta intrínsecamente en los dinamismos reales del sistema capitalista: nodos abusivos y/o superficiales y alienantes de buscar la propia seguridad y felicidad por la vía de la acumulación privada, del consumismo y del entretenimiento; sometimiento a las leyes del mercado consumista, promovido propagandísticamente, en todo tipo de actividades, incluso en el terreno cultural; insolidaridad manifiesta del individuo, de la familia, del Estado en contra de otros individuos, familias o estados.

La dinámica fundamental de venderle al otro lo propio al precio más alto posible y de comprarle lo suyo al precio más bajo posible, junto con la dinámica de imponer las pautas culturales propias para tener dependientes a los demás, muestra a las claras lo inhumano del sistema, construido más sobre el principio del hombre lobo para el hombre que sobre el principio de una posible y deseable solidaridad universal. La ferocidad depredaloria se conviene en el dinamismo fundamental y la solidaridad generosa se queda reducida a sanar incidental y superficialmente las heridas de los pobres, causadas por la depredación.

El hecho es que de los aproximadamente 400 millones de habilantes de 
América Latina, 170 millones viven en pobreza - los niveles de pobreza en el tercer mundo no son los mismos que los del primer mundo, pues los que en éste se estiman como tales (10,000 dólares familiares anuales en Estados Unidos), serían en aquél niveles de riqueza-, y de ellos 61 millones en pobreza extrema. Se necesitarlan 280,000 millones de dólares para superar esa situación, lo cual representa el 40 por ciento del PIB de América Latina. Pero esto se dificulta hasta casi la imposibilidad porque por el servicio de la deuda se da una exportación nela de capilal y ello sin contar con la fuga de capilales, que se estima mayor con mucho al conjunto de inversiones y ayudas extranjeras para toda la región. Esta realidad, fomentada tanto por el capilalismo internacional como por el capitalismo de cada una de las naciones, al ser debida no a la voluntad de las personas, sino a la estructura y a los dinamismos del sistema, es una prueba historica contundente de los males que el capitalismo ha traído o no ha podido evitar en América Latina.

Por otro lado, la propaganda ideologizada de la democracia capitalista como forma única y absoluta de organización política, se convierte en instrumento de ocultamiento y, a veces, de opresión. Ciertamente en el paquete democrático vienen valores y derechos muy dignos de tenerse en cuenta, sobre todo, si se llevan a sus últimas consecuencias y se crean las condiciones reales para disfrutarlos. Pero el manejo ideologizado del modelo democrático, lo que busca no es la autodeterminación popular respecto del modelo político y económico, sino el encuórimiento de la imposición del sistema capitalista y, sobre todo, en el caso de Centroamérica, de los intereses norteamericanos, de modo que en tanto se apoya la democracia en cuanto se supone se favorecerán esos intereses.

Por ello se aprecia más la seguridad nacional norteamericana que la autodeterminación de los pueblos, que el derecho internacional y aun el respeto de los derechos humanos fundamentales, a los que se defiende derivadamente, siempre que no pongan en peligro las estructuras militares y policiales, en las cuales se confía, más que en cualquier estructura democrática, para la defensa de los intereses norteamericanos. Se hace así punto de honor y de terribles decisiones, que afectan a millones de gentes, el problema de las elecciones y del disfrute de unos derechos civiles, que sólo los pueden utilizar activamente quienes tienen recursos materiales suficientes - los privilegiados económicamente-, mientras se exige con mucho menor vigor la superación de los asesinatos, de las desapariciones, de las torturas, etc., e incluso se emprenden acciones encubiertas por la CIA, entre las cuales no sólo se dan ilegalidades, sino estrictas prácticas terroristas.

Pero lo más grave es que la oferta de humanización y de libertad que hacen los países ricos a los países pobres no es universalizable y, consiguientemente, no es humana, ni siquiera para quienes la ofrecen. El agudo planteamiento de Kant podria aplicarse a este problema: Handle so, dass die Maxime deines 
Willens jederzeit zugleich als Prinzip einer allgemeinen Gesetzgebung gelten koenne (Kritk reinen Vernunfi, A 54). Si el comportamiento y aun el ideal de unos pocos no puede convertirse en comportamiento y en realidad de la mayor parte de la humanidad, no puede decirse que ese comportamiento y ese ideal sean morales y, ni siquiera humanos; cuanlo más, si el disfrule de unos pocos se hace a cosia de la privación de los más. En nuestro mundo, el ideal práctico de la civilización occidental no es universalizable, ni siquiera materialmente, por cuanto no hay recursos materiales en la tierra para que lodos los países alcanzacen el mismo nivel de producción y de consumo, usufructuado hoy por los países llamados ricos, cuya población no alcanza el 25 por ciento de la humanidad.

Esa universalización no es posible, pero tampoco es deseable. Porque el estilo de vida propuesto en y por la mecánica de su desarrollo no humaniza, no plenifica ni hace feliz, como lo demuestra, entre otros índices, el creciente consumo de drogas, constituido en uno de los principales problemas del mundo desarrollado. Ese estilo de vida está movido por el miedo y la inseguridad, por la vaciedad interior, por la necesidad de dominar para no ser dominado, por la urgencia de exhibir lo que se tiene, ya que no se puede comunicar lo que se es. Todo ello supone un grado minimo de libertad y apoya esa mínima libertad más en la exterioridad que en la interioridad. Implica asimismo un máximo grado de insolidaridad con la mayor parte de los seres humanos y de los pueblos del mundo, especialmente con los más necesitados.

Y si esta especie de ley histórica, que pretende ir configurando nuestro tiempo, apenas tiene algo de humano y es fundamentalmente inhumana, todavia más claramente debe decirse que es anticristiana. El ideal cristiano de encontrar la felicidad más en el dar que en el recibir - cuanto menos en el arrebatar(Hech 20,35), más en la solidaridad y en la comunidad que en el enfrentamiento y el individualismo, más en el desarrollo de la persona que en la acumulación de cosas, más en el punto de vista de los pobres que en el de los ricos y poderosos, queda contradicho e impedido por lo que es en la práctica, más allá del enunciado ideal que a nada compromete, el dinamismo real de los modelos actuales.

También hay una denuncia profética desde la realidad de América Latina sobre el modo de estructurarse y de comportarse la Iglesia institucional. La Iglesia latinoamericana ha sido demasiado tolerante con la siluación de injusticia estructural y de violencia institucionalizada predominantes en la región; sobre todo, hasta hace poco, la propia Iglesia universal ha sido ciega y muda frente a la responsabilidad de los palses desarrollados en relación con esa injusticia.

Ciertamente desde el tiempo de la conquista pueden presentarse ejemplos excepcionales de profetismo tanto en las bases como en la jerarquía de la Iglesia, pero junto a ello ha habido de forma preponderante posiciones de connivencia 
con mayor preocupación por intereses personales e institucionales que por las mayorías populares oprimidas y el reino de Dios. En nuestros días, Medellín y Puebla, a pesar de su gran mérito y valor, han tenido poco efecto real en las estructuras y comportamientos eclesiales. Los comportamientos martiriales como los de los obispos Romero, Valencia, Angelelli, elc., aunque no son del todo raros y excepcionales y han sido acompañados por decenas y aun centenares de laicos, religiosos y sacerdotes, hombres y mujeres, son muy significativos y alentadores, pero están lejos de ser la norma y no dejan de ser vistos como "peligrosos," como poco normales.

La Iglesia universal, siempre pronta a condenar el marxismo, ha sido mis tolerante con los males del capialismo, aun en sus formas más lacerantes de imperialismo. Hay claros avances desde el Valicano II y desde los últimos papas a este respecto; son también muy de apreciar algunas posiciones del episcopado norteamericano frente a la actilud de su gobicmo con los pueblos latinoamericanos. Pero práclicamente ha hecho falta llegar a la Solliciludo rei socialis para dejar las cosas definitivamente claras después del gran empuje en este sentido de la Gaudium et spes. Sin embargo, lo logrado en el plano doctrinal apenas ha pasado a la orientación pastoral y a una actitud más decididamente profética. La Iglesia que vive en los países ricos no denuncia con suficiente vigor el comportamiento explotador de esos países con el resto del mundo. Predica más la misericordia que la justicia, dejando así fuera uno de los ejes centrales del profetismo histórico. Se sigue temiendo más a los males del imperialismo soviético que a los males del imperialismo norteamericano y se prefiere tolerar los males actuales, generados por éste, que los potenciales, que pudieran venir de aquél.

Por otra parte, la Iglesia no ha hecho en América Latina un esfuerzo mínimamente suficiente por inculturarse en una situación muy distinta de la de los países noratlánticos. Se sigue pensando que hay un continuo histórico entre los países ricos y los paises pobres y se hace mayor caso de la unidad de lengua 0 de ciencia, que de la profunda ruptura del estado de desarrollo económico y de la posición que se ocupa en el orden económico intemacional. Se trata aquí de dos inculturaciones distintas o de dos fuentes de diversificación profunda, que la inculturación debiera tener en cuenta. Está, por un lado, la tremenda diferencia de culturas, de modos fundamentales de ser, originada por una serie compleja de factores (raciales, psico-sociales, linguísticos, educativos y de todo tipo). Por otro lado, está la diferencia asimismo fundamental del PNB, del ingreso per cápita, que imposibilita muchos de los modos culturales de los países ricos. No se trata sólo de las poblaciones indígenas o de color, sino de algo que afecta a todo el continente, si definimos el continente desde las mayorías populares. Se sigue pensando institucionalmente que a la hora del pensamiento teológico, de las formas de religiosidad, del mundo de los ritos, etc., América Latina sigue siendo un apéndice de Europa y una prolongación del catolicismo romano, 
cuando es una nueva realidad y, además, la realidad mayoritaria de la Iglesia calólica.

Esta realidad en sí misma es la que ella misma se convierte en denuncia profética y llama a una profunda transformación del modo de verse la Iglesia a sí misma y de entender su misión. Desoír este reclamo, amparados en la presunta inalterabilidad y universalidad de la fe y de la institucionalidad cristiana, es desoír la voz renovadora del Espíritu, que se presenta siempre con algún grado de proletismo; un profetismo que denuncia las limitaciones y los males que la Iglesia ha ido recogiendo como lastre en su caminar por la historia, que fundamentalmente ha sido la historia de los pueblos ricos, dominantes y conquistadores y no la historia de los pueblos pobres, que debió ser su matriz fundamental y que se perdió ya desde los tiempos de Constantino, aunque un importante residuo evangélico, el cual no cayó en la trampa de la riqueza ni del poder, siempre siguió vivo de las más distintas formas y siempre ha sido mal tolerado.

El profetismo de la denuncia, en el horizonte del reino de Dios, traza los caminos que llevan hacia la utopía. El no del profetismo, la negación superadora del profetismo, va generando el sí de la utopía, en virtud de la promesa, que es el reino de Dios, ya presente entre los hombres, sobre todo desde la vida, muerte y resurrección de Jesús, que ha enviado su Espíritu para la renovación, a través de la muerte, de todos los hombres y de todas las cosas.

La negación del particularismo reductor lleva a afirmar que sólo puede ser aceptable para la humanidad nueva un proyecto global que sea universalizable. Independientemente de toda consideración ética o teológica, no deja de ser válido el principio básico de que no es aceptable un orden ni una concepción del mundo, generadores cada vez de mayor número de gente en pobreza cada vez mayor, que sólo puede mantenerse por la luerza y la amenaza de destrucción total, que consituye ecológica y nuclearmente un peligro creciente de aniquilación de la humanidad, que no genera ideales de crecimiento cualitalivo, que se entrampa en ataduras de todo tipo. Por consideraciones puramente egoístas, donde el ego sea la humanidad entera y con él los egos de cada uno inviables a la larga sin la viabilidad de aquél, son necesarios cambios sustanciales en la concepción y en el dinamismo del llamado progreso.

Pero, más allá de todo realismo egoísta, de todo egoísmo realista, es claro que un orden favorable para unos pocos y desfavorable para la mayoría, es algo que deshumaniza y descristianiza a cada hombre y a la humanidad. Desde un punto de vista humano deberían medirse las acciones y los proyectos por el clásico "soy hombre y nada de lo humano me es extranto," signilicando con ello que cualquier alienación, cualquier acción u omisión que "extrañe" a otro hombre, descompone la propia humanidad de quien así se comporte. Desde un punto de vista cristiano, no cabe pasar de largo ante el herido en el camino, porque entonces se niega al prójimo - lo opuesto al "extraño"- y con ello se de- 
rrumban a la par el segundo y el primero de los mandamientos que el Padre ha renovado en el Hijo.

El principio de universalización ciertamente no es un principio de uniformización y, menos aún, de uniformización impuesta desde un centro poderoso a una periferia amorfa y subordinada, que es el camino de universalización pretendido por quien desea imponer aquel modelo de existencia, que le es de momento más favorable. Esta uniformización se rige hoy sobre todo por las leyes del mercado económico, como la expresión más contundente de que el materialismo, no histórico, sino económico, es el que en última instancia determina todo lo demás. Frente a él ha de generarse un universalismo no reductor, sino enriquecedor, de modo que la riqueza entera de los pueblos quede respetada y potenciada, y las diferencias sean vistas como plenificación del conjunto y no como contraposición de las partes, de modo que todos los miembros se complementen y en esa complementación el odo quede enriquecido y las partes potenciadas.

La universalización ha de hacerse desde la opción preferencial por los pobres, pues la hecha hasta ahora desde la opción preferencial por los ricos y poderosos ha traído más males que bienes a la humanidad.

Hasla ahora la universalización del orden histórico mundial y de la instiucionalización de la Iglesia se ha hecho desde una opción preferencial por los ricos y los poderosos. En el orden secular se ha hecho por los fuertes y para los fuertes, lo cual ha traído algunas ventajas en avances científicos, tecnológicos y culturales, pero sustentados éstos en grandes males para las mayorías, unas veces olvidadas, pero otras deliberadamente explotadas. También la Iglesia se ha mundanizado, esto es, ha seguido este comportamiento fundamental del "mundo" y ha configurado su mensaje y aun su institucionalización más desde el poder que domina y controla que desde el ministerio que sirve. Ambas instancias han vivido del principio, tan poco evangélico, de que dedicándose especialmente a los más ricos y siguiendo los patrones de comportamiento que favorecen a los más poderosos y a la acumulación del poder, es como mejor se sirve a las mayorias, a la humanidad y como mejor se propaga el evangelio. La pompa eclesial en imitación de la pompa real, el establecimiento de un poder político estatal, la sumisión a las leyes del mercado, etc., por parte de la Iglesia, muestran cómo ésta se ha sometido al principio mundano de que es la opción por el poder y por los poderosos lo que más asegura a las instituciones.

Ahora bien, éste no es el punto de vista cristiano. Desde el punto de vista cristiano ha de afirmarse que los pobres han de ser, no sólo el sujeto pasivo preferencial de quienes tienen poder, sino el sujeto activo preferencial de la historia, especialmente de la hisioria de la Iglesia La fe cristiana sostiene - y es ésta una cuestión dogmática que no puede ser contradicha, so pena de mutilar gravemente esa fe- que es en ellos donde se encuentra la mayor presencia real 
del Jesús histónico y, por lanto, la mayor capacidad de salvación (liberación). Los textos lundamentales de las bienaventuranzas y el del juicio final, entre otros, dejan saldado este punto con toda claridad. Muchas otras cosas se sostienen corno dogmáticas con muchísimo menor sustentamiento bíblico. Cơmo se deba concretar esta subjetualidad histórica y cómo deba ejercerse, es una cuestión abierta a discusiones teóricas y a experimentaciones históricas. Pero no por ello deja de ser un principio de discernimiento operativo el preguntarse siempre qué es lo más requerido por las mayorías populares para que puedan alcanzar realmente lo que les es debido como hombres y como miembros del pueblo de Dios.

En América Latina el profetismo hace más hincapié en el pobre activo y organizado, en el pobre con espíitu, que en el pobre pasivo, el pobre que sufre su miseria con resignación y sin apenas darse cuenta de la injusticia que sufre. No se niega la importancia, incluso profética del pobre por el mero hecho de ser pobre, pues no cabe duda de que ya como tal cuenta con una predilección especial de Jesús y una presencia suya muy particular. Pero cuando esos pobres incorporan espiritualmente su pobreza, cuando toman conciencia de lo injusto de su situación y de las posibilidades y aun de la obligación real que tienen frente a la miseria y a la injusticia estructural, se convierten de sujetos pasivos en activos, con lo cual multiplican y fortalecen el valor salvífico-histórico que les es propio.

Hay un argumento ulterior para ir en busca del nuevo ideal universal de hombre y de cristiano, del nuevo ideal de mundo y de humanidad desde las mayorias populares (versión secular) y desde los pobres (versión cristiana). Realmente, ellas representan la mayor parte de la humanidad. Esto significa, otra vez, desde el punto de vista negativo-profético que las distintas civilizaciones pasadas no han sido realmente humanas, sino clasistas y/o nacionalistas, y desde el punto de vista profético-utópico que debe apuntarse ineludiblemente al desarrollo-liberación de todo hombre y de todos los hombres, pero entendiendo que son "todos" los hombres quienes en algún modo condicionan el "todo" de cada hombre y que esos "todos" son en su mayor parte los pobres. Hasta ahora el desarrollo-liberación no ha sido de lodo el hombre ni va camino de serlo, lo cual se muestra en que lejos de llevar al desarrollo-liberación de todos los hombres ha llevado al subdesarrollo-opresión de la mayorfa de ellos. Se trala ciertamente de un largo proceso histórico, pero la pregunta es, si vamos en la dirección correcta o, al contrario, pese a todas las apariencias de mayor civilización, vamos hacia la deshumanización y descristianización del hombre.

En América Latina esta marcha profética hacia la utopla es impulsada por una gran esperanza. Fuera de toda retorica y a pesar de todas las dificultades, en el continente se dan ros de esperanza. La esperanza cristiana se conviente asf en uno de los dinamismos más eficaces para salir de la tienra de opresión y caminar hacia la lierra de promisión. 
Esta marcha de la opresión a la promisión está sustentada en la esperanza, que es recibida como gracia - no parecería que se dieran muchos molivos de esperanza frente a los enormes problemas y dificultades para que la esperanza se tomara como algo natural-, pero que se va alimentando históricamente y creciendo en la praxis de liberación. Es un hecho constatable cómo la esperanza, que anima a los pobres con espíritu, los alienta en largos y difíciles procesos, que a otros les parecen inútiles y sin futuro. Es una esperanza que se presenta, por tanto, con las características de la esperanza contra toda esperanza - característica muy cristiana-, aunque, una vez dada, se alimenta con los resultados obtenidos. No se trata del cálculo fijo que lleva a invertir con la calculada perspectiva de unos resultados deseables a plazo fijo, ni se trata tampoco de un suefo idealista que saca de la realidad, sino, más bien, de la aceptación de la promesa liberadora de Dios, una promesa fundamental que lanza a un éxodo, en el cual se conjugan propósitos y metas históricas con seguridades transhistóricas.

Frente al vacio del no sentido de la vida, que pretende llenarse con actividades y pretensiones sin-sentido profundo, los pobres con espíritu de América Latina son un signo real y operante de que hay en el mundo actual tareas llenas de sentido. En la crítica real, esto es, de la realidad esperanzada a la realidad sin esperanza, a la confusión que se da entre el estar entretenido o divertido y el ser feliz, entre el estar ocupado y el estar plenificado, se abre un espacio a oura forma de vida, completamente distinta a la que se impone hoy como ideal en una sociedad consumista, a la que se le proponen logros sin consistencia y sin sentido mayor. Ese espacio es el recorrido por los pobres con espiritu en una nueva disposición cristiana, que lleva a dar la vida por los otros, de modo que en esa entrega la encuentren al encontrarse a sí mismos; que lleva a poder despreciar todo el mundo, cuya conquista para nada importa, si supone la pérdida de sí mismo, del espíritu de uno mismo (Mc 8, $34-38$ y par.); que lleva a vaciarse de si mismo para, tras el vaciamiento, reencontrarse de nuevo en la plenitud de lo que se es y de lo que se puede ser (Fil 2, 1-11).

La esperanza de los pobres con espíritu es en América Latina -probablemente también en otros sitios-algo cualitativamente nuevo. No se trala de que la desesperanza absoluta lleve a un tipo de desesperación activa en aquellos hombres, que por no tener nada que perder, pueden lanzarse a perderio todo -el todo-nada de su propia vida, que resulta ya invivible). No hay desesperanza, sino esperanza y por eso la actilud y las acciones no son acciones desesperadas, sino actitudes y acciones que surgen de la vida y van en busca de mayor vida. Esto es un hecho constatable en miles de hombres y mujeres en campos de refugiados, entre las colonias marginales, entre los miles de desplazados, a quienes muchas veces no es el "esplritu político" el que los alienta, sino el "esplritu cristiano" el que los anima. Ese espiritu tendra que historizarse y politizarse para no evaporarse en subjetivismos inoperantes, pero la politización ni es lo primero ni es lo fundamental. 
Esta esperanza surgida de la vida, surgida a la par de la promesa y de la negación de la muerte, es celebrada festivamente. El sentido de fiesta, tal como se da en estos pobres con esperanza, indica por lo pronto que no se ha caído en el fanatismo de la desesperación y de la lucha por la lucha. Pero tampoco se cae por ello en la fiesta puramente diversionista, que caracteriza al mundo occidental carente de sentido y carente de esperanza. La fiesta no es el sustitutivo de la falta de esperanza, sino la celebración jubilosa de una esperanza en marcha. La búsqueda más o menos explícila de la felicidad se hace por otros caminos, que no la confuden sin más con el olvido drogado por el consumismo o con el mero consumismo de entretenimientos. No es sin más en el ocio donde se busca la plenitud, sino en la labor gratuita y gratificante de distintas tareas liberadoras.

En busca de una utopía universalizable históricamente, en la que los pobres o las mayorias populares tengan un lugar determinante y desde la esperanza que impulsa hacia ella se vislumbra una nueva revolución con el lema profético "comenzar de nuevo." Comenzar de nuevo un orden histórico, que transforme radicalmente el actual, fundamentado en la potenciación y liberación de la vida humana, es la llamada profética, que puede ir dando paso a una nueva utopía de inspiración cristiana.

"Comenzar de nuevo" no significa el rechazo de todo el pasado, lo cual ni es posible ni es deseable, pero significa algo más que simplemente ponerse a hacer cosas nuevas en desarrollo lineal con el hacer anterior. Significa un real "comenzar de nuevo," ya que lo viejo, en tanto que totalidad, no es aceptable, ni es tampoco aceptable el dinamismo principial (Zubiri) que lo impulsa.

El rechazo total del pasado no es posible ni aun en la más radical de las revoluciones y tampoco es deseable, porque priva a la humanidad de posibilidades, sin las cuales se vería obligada a comenzar de cero, cosa que es imposible. Además, no todo lo logrado es malo ni esta inficionado intrínsecamente de malicia. Hay elementos de todo tipo, científicos, culturales, tecnológicos, políticos, etc., cuya malignidad no proviene de ellos mismos, sino de la totalidad en la cual están inscritos y de la finalidad a la cual son sometidos. Se dan ciertamente elementos inaceptables, pero esto no es suficiente para abogar por un nihilismo imposible y estéril. En este sentido el "comenzar de nuevo" no supone ni aniquilación previa ni creación de un nuevo mundo desde la nada.

Pero tampoco se trata tan sólo de hacer cosas nuevas, sino más bien de hacer nuevas todas las cosas, dado que lo antiguo no es aceptable. Esto pertenece a la esencia del profetismo utópico. El "si no llegan a nacer de nuevo" (Jn 3, 3), la incorporación a la muerte que da vida (Rom 6, 3-5), la sernilla que necesita morir para dar fruto (Jn 12, 24), la desaparición y destrucción de la ciudad vieja para que surja la nueva en un mundo distinto (Apoc 18, 1 y ss.; 21, 1 y ss.) y tantos otros anuncios vetero y neotestamentarios ofrecen y exigen una transformación radical. $Y$ es que en la interpretación cristiana de la nueva vida, intercede 
siempre la muerte como mediación. Cicramente la buena nueva es un mensaje de vida, pero un mensaje de vida que asume, no sólo la realidad de la muerte, sino la vigencia posiuva de la negación de la mucre. Morir al hombre viejo, al mundo pasado, al eón antiguo, elc., es parte fundamental del mensaje bíblico. La profecía cristiana puede ir contra tal o cual hecho concreto, pero además y sobre todo va contra la totalidad de cualquier orden histórico, en el cual predomine el pecado sobre la gracia. Como negación y como afirmación la profecía utópica cristiana pretende hacer un hombre radicalmente nuevo y un mundo radicalmente distinto.

El principio fundamental sobre el que basar el orden nuevo sigue siendo el de que "todos tengan vida y la tengan en abundancia" (Jn 10, 10). Ese es el grito utópico nacido de la prolecía histórica. La experiencia histórica de la muerte - y no meramente del dolor-, muerte por hambre y miseria o muerte por represion y por distintas formas de violencia, al ser en América Latina tan viva y masiva, muestra la enorme necesidad y el valor insusuituible de la vida material, en primer lugar, como don primario y fundamental, sobre el cual han de radicarse todos los demás, que, en defínitiva, son desarrollo de ese don primario. Esa vida debe explayarse y plenificarse por crecimiento interno y en relación con la vida de los demás, siempre en busca de más vida y de vida mejor.

No es que sea evidente en qué consista la plenitud de la vida y menos aún cómo deba lograrse esa plenitud, pero no es tan difícil ver en qué no consiste y cómo no se va a lograr. Y esto no tanto por deducciones lógicas a partir de principios universales, sino por constatación histórica a partir de la experiencia de las mayorias populares. El buscar la vida quitándosela a los demás o despreocupándose de cómo los demás la van perdiendo, ciertamente es la negación del Espíritu como dador de vida. Desde esla perspectiva el mensaje básico cristiano de amar a los otros como a sí mismo y no solamente de no querer para sf lo que no se quiere para los otros, que formula pragmáticamente la "Declaración de los derechos del hombre y del ciudadano" (1793) en su artículo sexto; el propiciar más el dar que recibir y el proponer entregar todos los bienes a los más pobres, son ideales ulópicos, cuya historización profética puede ir generando esa novedad radical en los hombres y en las instituciones. Con ello no solo se impulsa a buscar algo radicalmente nuevo, sino que se trazan algunas líneas para intentar comenzar de nuevo, porque lo realizado hasta ahora no va por buen camino para beneficio de la mayor parte de la humanidad, constituida por mayorfas sin apenas acceso a la vida.

El profetismo histórico latincamericano se presenta en nuestros dras como liberación. La utopía de la libertad se pretende conseguir con el profetismo de la liberación. El ideal utópico de una plena libertad para todos los hombres no es posible más que por un proceso de liberación, de modo que no es primariamente la libertad la engendradora de liberación, sino que es la liberación la 
engendradora de la libertad, aunque entre ambas se dé un proceso de mutua potenciación y enriquecimiento.

Ha sido así históricamente. Las famosas liberties inglesas de la Charta Magna o del Bill of Rights son logros concretos - menos impuestos, juicios justos, protección contra la arbitraria dominación de los reyes, etc.- obtenidos por un proceso de lucha liberadora, mediante el cual se llega a la consecución de determinados derechos formalizados en pactos, leyes o constituciones. Se trata en el fondo de un proceso de liberación de la injusticia, de la dominación, del abuso institucionalizado y pseudojustificado. Sólo más tarde se ha hecho del liberalismo el modelo de libertad y el camino para preservar, más que para conseguir esa libertad. Pero la libertad real se obtiene fundamentalmente por un proceso de liberación. Esto es así en lo personal, en lo comunitario, en lo social y también en lo político. Por otro lado, el liberalismo, tal como es contradicho por el profetismo histórico de América Latina, es la cobertura jurídica y formal de quienes ya han sido liberados de ciertas opresiones y dominaciones y procuran, a su vez, que no lo consigan otros, respecto de ellos, por sucesivos y más complejos procesos de liberación.

Tanto la libertad personal como la social y política sólo son tales efectivamente cuando se "puede" ser y hacer lo que se quiere - se debe o es permitido - ser y hacer. La libertad sin condiciones reales que la hagan realmente posible puede ser un ideal, pero no es una realidad, ya que sin las debidas y suficientes condiciones, no se puede ser ni hacer lo que se quiere. Pero, si además de no darse las condiciones reales para ejercitar la libertad, las libertades y los derechos formales, se da una dominación y opresión positiva que impide aún más aquel ejercicio, es no sólo irreal sino positivamente ideologizado e hipócrita hablar de libertad. No hay libertad personal cuando, por ejemplo, se está dominado intermamente por fortísimos precondicionamientos o externamente por una presión propagandista no debidamente contrarrestada; no hay libertad personal, por ejemplo en el niño, cuando no se cuenta con el desarrollo intelectual y con los conocimientos mínimos para poder discemir y contrarrestar el peso de las motivaciones internas y externas; si, además, unos padres o unos educadores imponen de las más distintas formas sus ideas, actitudes o patrones de conducta, es ya casi sarcástico hablar de liberlad.

Lo mismo debe decirse de las libertades económicas y socio-polílicas. S6́lo las pueden disfrutar aquellos que tienen efectivo acceso a ellas y aquellos a quienes posilivamente no se les impide ese acceso por los medios más distintos, unas veces disfrazados y otras descubiertos. Qué libertad de movilización tiene el que carece de caminos, de medios de transporte y aun de fuerzas para caminar; qué libertad de elegir trabajo o estudio se da cuando sólo hay pueslos de trabajo - de estudio para el cincuenta por ciento de la población; qué libertad de expresión se da cuando el acceso activo a los medios sólo lo alcanza el uno por 
ciento y el acceso pasivo - por falla de alfabetización, por falta de aparatos, por falta de recursos, etc. - al sesenta por ciento; qué libertad economica se tiene cuando el acceso al crédito es cosa de poquisimos; qué libertad política se tiene cú́ndo no se cuenta con los recursos para hacer un partido político y cuándo los aparatos estatales o gremiales manienen un clima de terror 0 , al menos, de temor generalizado... Podrá decirse que el liberalismo no quiere idealmente nada de esio, sino que busca ofrecer igualdad de oportunidades para todos los individuos y lodas las tendencias. Pero de hecho esto no es así y el más mínimo ejercicio de historización muestra que las libertades y sus condiciones no se regalan, sino que se conquistan en un proceso histórico de liberación.

Una cosa es la liberalización y otra cosa muy distinta es la liberación. Los procesos de liberalización sólo son posibles si han antecedido procesos de liberación. La liberalización es problema de élites y para elites, mientras que la liberación es proceso de mayorías populares y para mayorlas populares, que empieza por la liberación de las necesidades básicas y construye después condiciones positivas para el ejercicio cada vez adulto de la libertad y para el disfrute razonable de las libertades. Que determinados procesos de liberación Liendan a convertirse en nuevos procesos de dominación de muchos por parte de pocos, es algo muy a tenerse en cuenta, pero no invalida la prioridad axiológica de la liberación sobre la liberalización a la hora de alcanzar la libertad.

Querer plantear el problema de la libertad al margen de la liberación es querer evadir el problema real de la libertad para todos. Ya en lo personal, la libertad no se actualiza plenamente, sino por laboriosos procesos de liberación frente a toda suerte de necesidades más o menos determinantes. Hay una base interna para la libertad y un ideal de libertad, que hasta cierto punto y de forma genérica le son dados "naturalmente" al hombre. Pero se trata fundamentalmente de capacidades y liberades, que necesitan ser actualizadas para convertirse en realidades plenas, para cuya actualización se requieren condiciones bien precisas. Con los debidos distingos algo similar debe decirse de la libertad social y política. Supone una liberación de estructuras opresoras y contra ellas lucharon los liberales clásicos en el supuesto de que sólo el Estado limitaba u oprimía al individuo, sin percalarse que hay grupos sociales que oprimian y explotaban a otros grupos sociales. Supone, además, la creación de condiciones para que la capacidad y el ideal de la libertad política y social puedan ser compartidos equitativamente.

La liberación se entiende, por tanto, como "liberación-de" toda forma de opresión y como "liberación-para" una libertad compartida, que no posibilite o permita formas de dominación. Tiene poco sentido hablar de libertad, cuando el espacio de su actualización está reducido por las necesidades básicas insatisfechas, por drásticas limitaciones de posibilidades reales entre las cuales elegir y por imposiciones de toda indole, especialmente las apoyadas en la fuerza 
y en el ternor. Pero no basta con una mera "liberación-de," pues se requiere una "liberación-para" o una "liberación-hacia" la libertad, que sólo podrá ser plena libertad, cuando sea libertad de todos. No es aceptable la liberad de unos pocos sustentada en la esclavitud de los demás, ni la libertad sustentada en la nolibertad de la mayoria. Por eso, aqui lambién, la libertad debe verse desde su hislorización en las mayorías populares dentro de cada país y de los pueblos oprimidos en el conjunto del mundo. Es la humanidad la que debe ser libre y no unos cuantos privilegiados de la humanidad, sean individuos, clases sociales 0 naciones.

Desde esta perspectiva el problema de la prioridad de la justicia sobre la libertad o de la libertad sobre la justicia se resuelve por la unidad de ambas en la liberación. No puede darse justicia sin libertad ni libertad sin justicia, aunque, en el orden social y político, haya una prioridad de la justicia sobre la liberlad, pues no se puede ser libre injustamente, mientras que la justicia, al dar a cada uno lo que le es debido, no sólo posibilita la libertad, sino que la moraliza y justifica. La liberación de toda forma de opresión, cualquiera que ésta sea, es como proceso real de justi-ficación, el medio real de potenciar la libertad y las condiciones que la hacen posible. En ese sentido la liberación es un proceso de "ajuste" consigo mismo, en cuanto busca desembarazarse de las cadenas interiores y exteriores; es un proceso "justo," en cuanto trata de superar una injusticia manifiesta; y es un proceso "justificador" en cuanto busca crear condiciones adecuadas para el desarrollo pleno de todos y para un equilativo uso de ellas.

En términos más explícitamente cristianos se trata de una marcha hacia la utopía de la libertad mediante un proceso real de liberación profélica, que implicaría la liberación del pecado, de la ley y de la muerte (Rom 6-8) y cuya meta consiste en que se revele efectivamente lo que es ser hijos de Dios, lo que es la libertad y la gloria de los hijos de Dios, cosa solo posible por un permanente proceso de conversión y liberación (Rom 8, 18-26), en seguimiento de Jesús mediante la reproducción personal de "los rasgos de su Hijo, de modo que éste fuera el mayor de una multitud de hermanos" (Rom 8, 29). Un desarrollo pleno de lo que es la liberación del pecado, de la ley y de la muerte pondría más en claro teológica e históricamente cómo la libertad es fruto de la liberación y cómo es peligroso plantear el problema de la libertad al margen de tareas precisas de liberación. Esto exigiría un tratamiento más extenso de este problema, pero su sola insinuación apunta a la necesidad imperiosa de procesos de liberación profécica para que la utopía de la libertad pueda realmente historizarse. 
4. La utopía criotiana, apuntada desde el profetiamo de Am6́rica Latina y, a su vez, orientada y regida por él, prenuncia de una manera historica la creación del hombre nuevo, de la tierra nueva y del cielo nuevo.

El hombre nuevo se dibuja desde el ideal cristiano, pero desde un ideal historizado, que pretende sustituir al hombre viejo, que ha venido siendo el ideal mundano y aun cristiano-mundano, propuesto como tal o, al menos, como un foco de atracción, prácticamente irresistible.

Para ello se parte de la convicción, alimentada tanto desde la fe como desde la experiencia histórica, de que el ideal y/o foco dominante de hombre mantenido en América Latina es anticristiano y no responde a los desaffos de la realidad. No lodo en ese ideal es imporado hasta el punto de que puede hablarse de una inculturación de ese ideal, la cual transmite rasgos propios a su historización. Prescindiendo ahora de cuales son los rasgos importados y cuales son los autoctonos puede hacerse un cierto catalogo de sus caracteristicas.

Respecto del hombre viejo dominante, como ideal, en la llamada civilización cristiana, noratlántica y occidental, se rechaza su radical inseguridad conducente a tomar medidas alocadas e irracionales de autodefensa, su insolidaridad con lo que le pasa al resto de la humanidad; su etnocentrismo junto con la absolutización e idolatrización de la nación-Estado como patria; su explotación y dominación directa o indirecta de los demás pueblos y de los recursos de esos pueblos; la superficialidad banal de su existencia y de los criterios con los cuales se eligen las formas de trabajo; la inmadurez en la búsqueda de la felicidad a traves del placer, del entretenimiento disperso y de la diversión; la pretensión autosuficiente de constituirse en vanguardia elitista de la humanidad; la agresión permanente al medio compartido por los otros.

El sentir los efectos multitudinarios, opresivos por un lado y disolventes por otro, de este hombre noroccidental sobre el hombre latinoamericano, hace que se rechace proféticamente su falso idealismo y que, sobre esa negación, se dibuje un hombre distinto. Pero, antes que eso, se rechaza que América Latina pertenezca sin más al mundo occidental y al mundo cristiano occidentalizado, porque, por medio de esta ideologización, se ha falsificado a Cristo, a quien se le convierte en cebo de una civilización no universalizable humanamente, pero que se busca exportar como modelo ideal de humanidad y de cristianismo. Cuando Hobbes en 1651 escribia en el Leviatín que las causas de las luchas entre los hombres son tres y que las tres están inscritas en la naturaleza humana - la inseguridad, la competencia y el deseo de gloria- estaba describiendo más la experiencia del hombre occidental emergente que algo necesariamente insito en la naturaleza humana. Cuando el cristianismo oficial convierte en virtudes opcionales e intencionales lo que debería ser la negación real de actitudes y hechos anticristianos, está lambién haciendo una lectura interesada de la fe, que anula la verdad real y la efectividad de la misma. 
La vuelta al realismo histórico del anuncio evangélico, realismo histórico que de ninguna manera es fundamentalista, precisamente porque es histórico, obliga a volver sobre el tema evangélico fundamental riqueza-pobreza. La lectura interesada de la fe ha hecho posible conciliar la riqueza material con la pobreza espiritual, cuando la lectura verdadera, atestiguada por los mayores santos de la Iglesia, es la opuesta: conciliación de la pobreza material con la riqueza espiritual. Pues bien, la comprobación historica de la relación dialéctica riquezapobreza recupera la profundidad del mensaje evangélico, haciendo de la pobreza no un consejo puramente opcional, sino una necesidad histórica; haciendo correlativamente de la riqueza no algo indiferente conciliable fácilmente con el seguimiento de Jesús, sino uno de los impedimentos fundamentales de la constitución del reino. Se habla aquí no de la pobreza y riqueza por separado, sino en su relación dialéctica: la pobreza como correlato de la riqueza y la riqueza como correlato de la pobreza.

No sólo desde el punto de vista de la fe, sino también desde el punto de vista de la historia, se ve en la riqueza y en la concupiscencia o afán de la riqueza el motor de una cultura desalmada e inhumana y la resistencia mayor a la construcción histórica del reino de Dios. El camino del enriquecimiento rápido y desigual ha llevado a la ruptura caínita de la humanidad y a la formación de un hombre explotador, represivo y violento. La relación del hombre con la riqueza, tan esencial en el evangelio, vuelve a constituirse en punto central en la definición del hombre nuevo. No se dará el hombre nuevo mientras no se logre una relación totalmente nueva con el fenómeno de la riqueza, con el problema de la acumulación desigual. Este problema, que se intentó resolver por la vía de la ascética y de la espiritualidad individual o grupal, ha de retomarse porque se ha convertido en una necesidad histórica para frenar la deshumanización de ricos y pobres dialécticamente enfrentados.

Tras el señuelo de la riqueza, de los hombres y de los pueblos ricos, se pierden las señas de la propia identidad. El buscar la propia identidad en la apropiación desvirtuada de modelos extraños, lleva a dependencias y mimetismos, frenadores de la propia autocreación. La cultura de la riqueza propone modelos y establece medios para conseguirlos y lo hace de tal modo que obnubila la posibilidad de buscar otros modelos de plenitud y felicidad y somete a dinamismos alienantes a todos cuantos se dedican a adorar al becerro de oro. El becerro de oro se convierte en el ídolo central de una cultura nueva, la cual, a su vez, refuerza el papel central que juega en ella. Allí donde está tu tesoro está tu corazón, que queda con ligurado con las características propias del lesoro. De ahr la importancia en la elección del tesoro. Cuando éste se confunde con la acumulación de la riqueza, el tipo de corazón y de hombre que resultan de ello se ven sometidos a una doble alienación: la de someter la propia libertad a los dinamismos necesitantes y cosificantes del dinero y la de someter la propia identidad a un modelo creado no para la liberación, sino para la sumisión. 
Ciertamente, la riqueza cuenta con algunas posibilidades de liberación, pero a costa de otras posibilidades de esclavitud propias y ajenas.

Todos estos males, en gran parte inducidos desde fuera, son acompanados y reflejados por otros surgidos más desde dentro. Tendencias machistas y violentas, que degradan tanto al hombre como a la mujer, reflejadas en profundas desviaciones de la vida sexual y familiar, o todo un cojunto interdependiente de sumisión, fatalismo e inercia son ejemplo de ello. Cuánto tengan de ancestral e incluso de natural y cuánto de reflejo de esúmulos exteriores es cuestión de investigarlo en cada caso. Pero no sería buen camino para retomar la propia identidad situar el origen de todos los males en agentes externos, porque esto dificultaria la tarea de construir desde dentro el hombre nuevo.

La ideologización correspondiente a este conjunto de hechos y tendencias reales se demuestra a si misma como negativa y anuladora de la propia conciencia individual y colectiva. Esa ideologización se presenta cono religiosa, económica o política, y lo que hace, en el fondo, es reforzar los intereses fundamentales latentes o explicitos. El fatalismo religioso, la competencia econónica de la libre empresa y el afán de lucro, el sistema democrático ofrecido como una participación controlada y pautada de las mayorias populares, son ejemplos de esla ideologización, apoyada en algunos bienes y valores, pero transmisora de males mayores.

Lo anterior en su negatividad apunta a lo que deben ser positivamente los rasgos de la ulopía. Esa negatividad a la luz de la inspiración cristiana sefiala lo que ha de ser el hombre nuevo como contrapuesto al hombre viejo. Como no se trata primordialmente de un ejercicio intencional, sino de una praxis ya en marcha, algunos de esos rasgos son apreciables en lo que ya se está dando.

El punto central tiene que ver con la opción preferencial por los pobres como modo fundamental de combatir la prioridad de la riqueza en la configuración del ser humano. Se va hacia una mayor solidaridad con la causa de los oprimidos, a una creciente incorporación a su mundo como lugar privilegiado de humanización y de divinización cristiana, no para regodearse en una pobreza miserable, sino para acompanar a los pobres en su anhelo de liberación. La liberación no puede consistir en un paso de la pobreza a la riqueza haciéndose ricos con la pobreza de los otros, sino en una superación de la pobreza por la via de la solidaridad. Se trata eso si de los pobres con espíritu, de los pobres que asumen su situación como fundamento en la construcción del hombre nuevo. Desde la materialidad de la pobreza, Esta se levanta activamente desde los pobres con espíritu hacia un proceso de liberación solidaria, que no deja fuera a ningún hombre. Dicho de otro modo, se trata de unos pobres activos, a quienes la propia necesidad aguijonea para salir de una situación injusta.

De ahí que este hombre nuevo se defina en parte por la protesta activa y la lucha permanente, las cuales buscan superar la injusticia estrucural dominante, 
considerada como un mal y como un pecado, pues mantienen a la mayor parte de la población en condiciones de vida inhumana Lo negativo es esta sibuación, que en su negatividad lanza como un resone a salir de ella; pero lo positivo es la dinámica de superación, en la cual alienta el Espíritu de múluples formas, siendo la suprema de todas la disponibilidad de dar la vida por los demás, sea en la entrega cotidiana incansable o en el sacrificio hasta la muerte, padecida violentamente.

Típico, sin embargo, de este hombre nuevo, movido por el Espíritu, es que su motor no es el odio, sino la misericordia y el amor, porque ve en todos a hijos de Dios y no a enemigos por destruir. El odio puede ser lúcido y eficaz a corta distancia, pero no es capaz de construir un hombre realmente nuevo. El amor cristiano no es precisamente blando, pero sí pretende muy decididamente no dejarse entrampar por el egoísmo ni por el odio y tiene una muy clara vocación de servicio. Son los seffores de este mundo, quienes pretenden dominar y ser servidos, mientras que el Hijo del hombre, el hombre nuevo, no ha venido a ser servido, sino a servir y a dar su vida por los demás, por los muchos (Mt 20, 2528).

Junto al amor la esperanza. El hombre nuevo para ser realmente nuevo ha de ser hombre de esperanza y de alegria en la construcción de un mundo más justo. No lo mueve la desesperación, sino la esperanza, porque aquella propende al suicidio y a la muerte y ésta a la vida y al don. Será a veces esperanza contra toda esperanza, pero en eso mismo es perceptible la alegría y la seguridad de alguien por encima del hombre y de sus pensamientos, el impulso de una vocación a construir el reino, que fundamentalmente es reino de Dios, porque es Dios su meta final y su motor constante. América Latina, que tantas veces ha sido llamado el continente de la esperanza, lo es en multitudes de hombres llenos de esperanza y no meramente como una mera potencialidad natural todavía no desarrollada.

Es una esperanza abierla e incansable. El hombre nuevo es un hombre abierto, que no absolutiza ningún logro en el engaño de hacer de algo limitado algo infinito. El horizonte es necesario como límite que orienta, pero es más necesario como apertura permanente para quien avanza. La absolutización de la riqueza, del poder, de la organización, de la institución, elc., convertidas en ídolos, hacen del idólatra un hombre cerrado y sometido, todo lo contrario del hombre abierto a un Dios siempre mayor y a un reino que ha de historizarse permanentemente en una aproximación cada vez mayor, pero que por múltiples motivos supera cada logro parcial y lo supera cualilativamente por el desciframiento de novedades lógica y conceptualmente imprevisibles.

Se llega así no sólo a una nueva relación entre los hombres, sino también a una nueva relación con la naturaleza. Cuando los primitivos pobladores de América Latina sostenlan que la tierra no puede ser poseída por nadie, no puede 
ser propiedad de nadie en particular, porque es una diosa madre, que da la vida a tantos hombres, sostenían una respetuosa y venerada relación con la naturaleza La naturaleza no puede ser vista meramente como materia prima o lugar de inversión, sino como manifestación y don de Dios, que ha de ser disfrubada con veneración y no maltratada con desprecio y explotación.

Para hacer todo esto posible se dibuja un hombre nuevo, contemplativo y activo a la vez, un hombre superador tanto del ocio como del negocio. Ni la actividad es suficiente ni la contemplación es bastante. Contra la tentación de la pereza, encubierta en el ocio de la contemplación, lo urgente de la tarea impulsa a una acción eficaz, pues la gravedad de los problemas no permite espera. Contra la tentación del activismo, encubierta como creación constante de nuevas oportunidades, lo vaclo y destructor de sus promesas exige la riqueza de la contemplación. La acción sin contemplación es vacía y destruclora, mientras que la contemplación sin acción es paralizante y encubridora. El hombre nuevo es oyente y hacedor de la Palabra, escrutador de los signos de los tiempos y realizador de lo que se le ofrece como promesa.

Ouros rasgos históricos de la vida de Jesús deberían ser proyectados también en este hombre nuevo, que ya apunta concretamente en el horizonte latinoamericano de los pobres y de quienes han echado su suerte con ellos. Pero los aquI apuntados, sobre todo cuando hacen referencia explícita a un Dios siempre presente, en el cual confiar y al cual confiar el sentido último de la semilla sembrada, son los que unifican y matizan esos otros rasgos históricos de la vida de Jesús, que son asumidos con distintos matices y, sobre todo, con diferentes concreciones según la vocación particular de cada persona.

Entre la negación superadora del hombre viejo y la realización afirmativa del hombre nuevo, entre el profetismo que niega arimando y la ulopía que afirma negando, la praxis latinoamericana de la fe cristiana va abriendo nuevos caminos, buenos en definitiva para todos los hombres, buenos para la construcción de una tierra y de un mundo nuevos.

La creación de la nueva tierra implica la utopía de un nuevo orden económico, un nuevo orden social, un nuevo orden político y un nuevo orden cultural. El llamado nuevo mundo, lejos de ser realmente nuevo, se convirti6, sobre todo en el subcontienente latinoamericano, en un remedo empobrecido del viejo, y solo ahora se estaría en disposición, una vez fracasado el modelo anterior, de levantar sobre su negación un mundo realmente nuevo.

No se trata de quedarse en idealismos voluntaristas. Hay una inercia histórica, unas leyes cuasi necesarias y un peso de la tradición, que no pueden ser abolidos, pero que deben ser contrarrestados y en lo posible transformados por la fuerza del ideal utópico, surgido de la necesidad objetiva, y no meramente intencional, de superar los males gravisimos y universales del presente. No se puede 
desconocer la existencia de dinamismos propios de la evolución histórica, nunca dominados completamente por sujeto histórico alguno. Pero no por ello ha de aceptarse un determinismo histórico absoluto, que llevaría al fatalismo o que tan sólo permitiría, en el mejor de los casos, el intento de mejorar el todo estructural por la superación de cada individuo o de algunos de los grupos sociales. La propuesta alternaliva de "salvese quien pueda" en este desorden mundial, puede suponer la solución momentánea para unos pocos, pero supone la ruina de la mayoría. Por eso es necesaria la utopía, el recurso al ideal utópico, constituido en fuerza efectiva asimilada por muchos, para contrartestar y aun dirigir lo que de otra forma se constituye en el curso ciego y mecánico de la historia. No es cierto que la libertad de cada uno llevará a la libertad de todos, cuando la recíproca es mucho más real: la libertad general es la que posibilitará la liberıad de cada uno. Y ese ideal de hacer real la utopia puede constituirse en principio de libertad y de espiritualidad, que se incorpore, a través de la subjetividad de las personas, al determinismo y a la materialidad de los procesos históricos. Desde esta perspectiva podría leerse de una forma radicalmente nueva el famoso pasaje de Marx en la Contribución a la crítica de la filosofla del derecho de Hegel (1844): "es cierto que el arma de la crítica no puede sustituir a la crítica de las amas, que la fuerza material debe ser derrocada por la fuerza material, pero también la teoria se convierte en poder material tan pronto como se apodera de las masas." El ideal utópico, cuando se presenta históricamente como realizable paulatinamente y es asumido por las mayorias populares, llega a convertirse en una fuerza mayor que la luerza de las armas, es a la vez, una fuerza material y espiritual, presente y futura, capaz por tanto de superar la complejidad materialespiritual, con que se presenta el curso de la historia.

En el orden económico la utopía cristiana, vista desde América Latina, que surge del profetismo real historizado en una situación determinada, propone una civilización de la pobreza, que sustimya a la actual civilización de la riqueza. Desde una perspectiva más sociobogica que humanista esta misma utopía se puede expresar mediante la propuesta de una civilización del trabajo, que sustituya a la civilización dominante del capital.

Si el mundo como totalidad se ha venido configurando sobre todo como una civilización del capital y de la riqueza, en el que aquél más objetivamente y ésta más subjetivamente han sido los principales elementos motores, conformadores y directores de la civilización actual, y si esto ha dado ya de sí todo lo positivo que tenia y estŕ trayendo actualmente cada vez mayores y más graves males, ha de propiciarse, no su corrección, sino su suplantación superadora por su contrario, esto es, por una civilización de la pobreza. Desde los tiempos de Jesús siempre que se sobrepone la pobreza a la riqueza para entrar en el reino, se suscita un gran rechazo, sobre todo por parte de quienes ya son ricos o han puesto en la riqueza el fundamento indispensable de sus vidas. Pero lo que Jesús proponía como ideal personal puede y debe ampliarse a la realidad socio-histórica, hecha 
la debida adecuación.

La civilización de la riqueza y del capital es aquella que, en última instancia, propone la acumulación privada del mayor capital posible por parte de individuos, grupos, mulunacionales, estados o grupos de estados, como la base fundamental del desarrollo y la acumulación poseedora, individual o familiar, de la mayor riqueza posible como base fundamental de la propia seguridad y de la posibilidad de un consumismo siempre creciente como base de la propia felicidad. No se niega que tal tipo de civilización, vigente tanto en el este como en el oeste y que debe llamarse civilización capitalista - sea capilalismo de Estado o capitalismo privado-, ha traido bienes a la humanidad, que como tales bienes deben ser conservados y propiciados (desarrollo científico y técnico, nuevos modos de conciencia colectiva, etc.), pero han traido males mayores y sus procesos de autocorrección no se muestran suficientes como para revertir su curso destructor.

En consecuencia, visto el problema en su totalidad mundial desde la perspectiva de las necesidades reales y de las expectativas de la mayor parte de la población mundial, esa civilización de la riqueza y del capital ha de ser superada radicalmente. En este punto a los reclamos ya antiguos de la teología de la liberación ha venido a antadirse de forma muy significativa la doctrina social de la Iglesia, sobre todo en su nueva formulación de la Laborem exercens de Juan Pablo II. El economicismo materialista, que configura la civilización de la riqueza, no es aceptable éticamente en su propio dinamismo interno y, mucho menos, en sus resultados reales. En vez del economicismo materialista debiera plantearse un humanismo materialista, que reconociendo y, por tanto, apoyándose en la condición complejamente material del hombre, evade todo tipo de solución idealista a los problemas reales del hombre. Este humanismo materialista intenta superar el economicismo materialista, ya que no sería la materia económica la que determinase en última instancia todo lo demás, lo cual sí se da en cualquier lipo de civilización del capital y de la riqueza, sino la materia humana, compleja y abierna, que concibe al hombre como sujeto limitado, pero real, de su propia historia.

La civilización de la pobreza, en cambio, fundada en un humanismo materialista, transformado por la luz y la inspiración cristiana, rechaza la acumulación del capial como motor de la historia y la posesión-disfrute de la riqueza como principio de humanización, y hace de la satisfacción universal de las necesidades básicas el principio del desarrollo y del actecentamiento de la solidaridad compartida el fundamento de la humanización.

La civilización de la pobreza se denomina así por contraposición a la civilización de la riqueza y no porque pretenda la pauperización universal como ideal de vida. Ciertamente la tradición cristiana, estrictamente evangélica, tiene una enorme desconfianza con la riqueza, siguiendo en esto la enseflanza de Jesús, 
mucho más clara y contundente de lo que pueden ser otras que se presentan como tales. Asimismo los grandes santos de la historia de la Iglesia, muchas veces en manifiesta pugna reformista contra las autoridades eclesiales, han predicado incesantemente las ventajas cristianas y humanas de la pobreza material. Son dos líneas que no pueden ser pasadas por alto, porque en el caso de los grandes fundadores religiosos - véase, por ejemplo, el caso de san Ignacio de Loyola en sus deliberaciones sobre la pobreza-, se hace referencia explícita no sólo a lo individual-personal, sino también a lo insitucional. Pero, aun admitiendo y teniendo en cuenta tales consideraciones, que ponen en entredicho a la riqueza en sí misma, lo que aquí se quiere subrayar es la relación dialéclica riqueza-pobreza y no la pobreza en sí misma. En un mundo configurado pecaminosamente por el dinamismo capilal-riqueza es menester suscitar un dinamismo diferente que lo supere salvíicamente.

Esto se logra, por lo pronto, mediante un ordenamiento económico apoyado en y dirigido directa e inmediatamente a la satisfacción de las necesidades básicas de todos los hombres. Sólo esta orientación responde a un derecho fundamental del hombre, sin cuyo cumplimiento se irrespeta su dignidad, se violenta su realidad y se pone en peligro la paz mundial.

Sobre cuáles sean las necesidades básicas, aun contando con diferencias culturales e individuales, propiciantes de distintas subjetivizaciones de esas necesidades, no cabe gran discusión, si se atiende a la situación de pobreza extrema o de miseria de más de la mitad del género humano. Como tales deben considerarse, ante todo, la alimentación apropiada, la vivienda mínima, el cuidado básico de la salud, la educación primaria, suficiente ocupación laboral, etc. No se trata de proponer que esto agote el horizonte del desarrollo económico, sino que esto se conslituya en punto de partida y en referencia fundamental, en condición sine qua non de cualquier tipo de desarrollo. La gran tarea pendiente es que todos los hombres puedan acceder dignamente a la salisfacción de esas necesidades, no como migajas caídas de la mesa de los ricos, sino como pare principal de la mesa de la humanidad. Asegurada insutucionalmente la satisfacción de las necesidades básicas como fase primaria de un proceso de liberación, el hombre quedaría libre para aquello que deseara ser, siempre que lo deseado no se convierta en nuevo mecanismo de dominación.

La civilización de la pobreza propone, como principio dinamizador, frente a la acumulación del capital, la dignificación por el trabajo, un trabajo, que no tenga por objetivo principal la producción de capital, sino el perfeccionamiento del hombre. El trabajo, visto a la par como medio personal y colectivo para asegurar la satisfacción de las necesidades básicas y como forma de autorealización, superaría distintas formas de auto y de helero-explotación y superaría asimismo desigualdades no sólo hirientes, sino causantes de dominaciones y antagonismos. 
No se trata sólo de que el hombre nuevo deje de hacer de la riqueza su ídolo fundamental, al cual ofrece todo lo que tiene: capacidad de trabajo, principios morales, salud, ocio, relaciones familiares, etc. Se trata, sobre todo, de hacer una sociedad que, negativamente, no obligue a hacer de la riqueza el valor supremo, porque sin él todo se pierde - $l$ de qué le sirve al hombre salvar su alma, que no se ve ni se estima, si se pierde el mundo que se ve y que es lo que más se estima? - y que, positivamente, se estructure de tal modo, que no se requiera el andar buscando la riqueza para contar con todo lo necesario para la liberación y plenificación del hombre. Es claro que una sociedad no estructurada por las leyes del capital y que dé la primacía al dinamismo del trabajo humanizador estaria configurada de un modo muy distinto de la actual, porque su principio configurador es totalmente distinto. El fracaso humanista y moral de la sociedad actual, de la tierra actual, configurada, según los diclados del capital, ya va impulsando de distintas formas a las vanguardias más o menos marginales para que configuren una sociedad distinta, aunque sea de momento saliéndose de las estructuras y dinamismos de la actualmente dominante. La solución defunitiva, sin embargo, no puede estar en un salirse de esle mundo y hacer frente a él un signo de protesta profético, sino en introducirse en él para renovarlo y uransformarlo hacia la utopia de la tierra nueva.

En parte esto se irá logrando, si se robustece positivamente una característica fundamental de la civilización de la pobreza, la solidaridad compartida, en contraposición con el individualismo cerrado y competitivo de la civilización de la riqueza. El ver a los otros no como parte de uno mismo, sino verse a sl mismo en unidad y comunión con los otros, se conjuga bien con lo más hondo de la inspiración cristiana y aparece en consonancia con una de las mejores tendencias de los sectores populares latinoamericanos, que se abre frente a tendencias individualistas disociadoras. Esta solidaridad se posibilita en el disfrute común de los bienes comunes.

No se necesita la apropiación privada de los bienes comunes para cuidar y disfrutar de ellos. Cuando la doctrina social de la Iglesia, siguiendo a santo Tomás, mantiene que la apropiación privada de los bienes es la mejor manera práctica para que el destino común primordial de ellos se cumpla de manera ordenada, está haciendo una concesión "a la dureza de sus corazones," pero "en el principio no fue así." Sólo por la avaricia y el egoísmo, connaturales al pecado de origen, puede decirse que la propiedad privada de bienes es la mejor garantla del avance productivo y del orden social. Pero, si el "donde abundó el pecado, sobreabundó la gracia" va a tener verificación histórica, es menester anunciar utópicamente, que una tierra nueva con hombres nuevos debe configurarse con principios más altruistas y solidarios. Los grandes bienes de la naturaleza (el aire, los mares y las playas, las montañas y los bosques, los ríos y lagos, en general el conjunto de los recursos naturales para la producción, el uso y el disfrute) no necesitan ser apropiados privadamente por ninguna persona individual, grupo 0 
nación y de hecho son el gran medio de comunicación y conviviencia.

Si se lograra un orden social, en el cual quedaran satisfechas de modo estable y garantizado las necesidades básicas y quedaran posibilitadas las fuentes comunes del desarrollo personal, de modo que quedaran garantizadas la seguridad y las posibilidades de personalización, podría estimarse como etapa prehistórica y pre-humana, la fundamentada en la acumulación de capilal privado y de riqueza material. El objetivo utópico no es que todos tengan mucho por la vía de la apropiación privada y exclusivista, sino que todos tengan lo necesario y quede abierto a wodos el uso y disfrute no acaparador y exclusivista de lo que es primariamente común. No puede confundirse el dinamismo indispensable de la iniciativa personal con el dinamismo natural-original de la iniciativa privada y privatizadora. Ni la única manera de urabajar para sí mismo, ni de ser sí mismo, es la de excluir a los otros como competidores de mi mismidad.

Aquel ordenamiento económico que esté orientado por estos principios y que favorezca el desarrollo del hombre nuevo, dcbe ser el ordenamiento utópico nuevo de una economía al servicio dcl hombre, que ciertamente llevaria a una tierra nueva. Hoy es un reclamo compartido quc en la actualidad el hombre se somete a la economía y no la economía al hombre. Aunque este fenómeno indica, entre otras cosas, el predominio de lo común y estructural sobre lo individual coyuntural, el modo de presentarse el fenómeno - la dominancia de lo económico sobre lo humano- no es aceptable como ideal utópico y, mucho menos, es compatible con el ideal cristiano.

¿Cuál de los dos grandes ordenamientos económicos hoy disponibles, el capitalista y el socialista, se acomoda mejor a la consecución de ese ideal utópico?

En América Latina es baslante claro el fracaso de los modelos capitalistas, que han sido los claramente dominantes en ella durante decenios. Se dirá que no han sido suficientemente capitalistas, pero, si es que ha sido asl, no lo ha sido por oposición al capitalismo, sino por la incapacidad objetiva de imponer un sistema capitalista en una situación como la latinoamericana. Los sistemas capitalistas en América Latina han sido incapaces de satislacer las necesidades básicas de la mayor parte de la población, han creado desigualdades hirientes entre los pocos que tienen mucho y los muchos que tienen poco, han llevado a una gigantesca deuda extema impuesta sobre los hombres que para nada disfrutaron ni sacaron provecho de los préstamos, han producido con frecuencia crisis económicas profundísimas y han promovido una cultura inmoral del consumismo y de la ganancia fácil. Tristemente todo esto se ha hecho por hombres y clases que se consideran católicas y que no ven contradicción entre su praxis económica y su praxis cristiana. Desde esta realidad lo menos que puede decirse es que sólo una transformación radical del ordenamicnto cconómico capitalista es mínimamente conciliable con lo que es la utopía cristiana. El marxismo, en cuanto es el gran 
contradictor de ese ordenamiento, en cuanto ataca a fondo el espíritu del capitalismo y analiza los mecanismos que lo sustentan y en cuanto utópicamente anuncia la liberación del hombre por la liberación del trabajo, desempena en América Latina un rol profélico y utópico de gran alcance y ofrece mélodo científico para desentrañar los dinamismos profundos del sistema capitalisla.

Por otro lado, los resultados económicos - luego volveremos sobre los políticos- de los ordenamientos socialistas tampoco son satisfactorios, al menos para entrar en la competencia mundial. Los recientes intentos de las mayores naciones socialistas para corregir sus sistemas económicos con procedimientos más propios del sistema opuesto, sin significar el abandono de lo principial del propio, apuntan a algunas limitaciones muy dignas de tenerse en cuenta. Por otra parte, sería prematuro condenar de antemano al fracaso los modelos socialistas reformados por lo que está ocurriendo actualmente en Nicaragua, aunque sería un error desconocer las dificultades reales que ese sistema tiene en el modo concreto de darse, atendidos los lugares y los tiempos. Incluso el modelo cubano, aun habiendo logrado en un tiempo relativamente breve la mejor satisfacción de las necesidades básicas de todo el continente latinoamericano, no deja de tener dificultades intrínsecas, que sólo con un apoyo masivo exterior pueden ser superadas. Por lo tanto, también se dan problemas graves en la realización del modelo socialista como instrumento más eficaz para historizar la utopía cristiana.

Sin embargo, puede sostenerse que el ideal socialista está más cerca en lo económico de las exigencias utópicas del reino. El ideal económico socialista se apoya en valores profundos del hombre y no prospera económicamente precisamente por su idealismo moral, que no tiene en cuenta el estado empírico de la naturaleza humana. El ideal económico capitalista se apoya, al menos parcialmente, en los vicios egoístas de la naturaleza humana y es, en ese sentido, no más realista, pero sí más pragmático que su oponente, por lo cual tiene exitos economicistas superiores. Diriase, por tanto, que, si se lograra el hombre nuevo, el ordenamiento socialista funcionaría mejor, mientras que bajo el dominio del hombre viejo funcionan mejor unas estructuras que, lundamentalmente, son injustas para la mayor parte de la población mundial. Por ello, aunque no se puede ser ingenuo al recomendar una u otra mediación del reino, la utopía cristiana que trabaja por el hombre nuevo en una tierra nueva, no puede menos de inclinarse en lo económico por formulaciones más próximas al socialismo que al capitalismo en lo que se refiere a América Latina y, más en general, al tercer mundo. No está de más recordar que la enseflanza social de la Iglesia va acercándose más a este modo de ver las cosas.

Puede objetarse que en los paises capitalistas está mejor asegurada la satisfacción de las necesidades básicas que en los países socialistas. Pero la objeción no es tan sólida, si se tiene en cuenta, primero, que los países capitalistas atienden a una parte mucho menor de la población mundial; segundo, que eso se logra con altísimos costos de una gran parte de esa población y, 
tercero, que ese sistema no es universalizable, dados los limitados recursos mundiales y la apropiación privada de los mismos por unos pocos países privilegiados.

En ambos casos, aunque de manera desigual según sean las situaciones, el profetismo y la ulopía cristiana necesitan ser críticos de la tcorfa y de la práctica de los sistemas económicos dominantes. A veces la enseñanza social de la Iglesia ha sido demasiado ingenua y tolerante con la teoria y, sobre todo, con la práctica del capitalismo por el miedo a perder prebendas y por el miedo a los regímenes marxistas. Pero también la toología de la liberación ha sido en ocasiones ingenua y tolerante con la teoria y la práctica del marxismo por un cierto complejo de inferioridad ante el compromiso de los revolucionarios. Sin pasar por alto la difícil relación del profetismo y de la utopía con las mediaciones históricas, que no deben ser anatematizadas desde un purismo irreal, lo que finalmente importa subrayar es que, en cualquiera de los casos, la civilización del trabajo y de la pobreza debe sustituir a la civilización del capital y de la riqueza. Y parecería lo cual no deja de plantear un problema gravísimo- que se va imponiendo mundialmente la civilización del capital y de la riqueza, tanto en los casos del capilalismo privado como en los casos del capitalismo estatal. De ahí que al profetismo y a la utopia cristianos les quede una permanente tarea de levadura.

Correspondiente a ese nuevo orden económico debe surgir un nuevo orden social vigoroso y pluripolar, en el cual se posibilite el que el pueblo sea cada vez más sujeto de su propio destino y tenga mayores posibilidades de libertad creativa y de participación. Como el pueblo de Dios es el que debe tener la prioridad en el reino de Dios y no un conjunto de superestructuras institucionales, que hagan sus veces, también en la historia de este mundo deben ser los grupos sociales, quienes lleven el peso de la historia y lo lleven desde sí mismos. Dicho en otros términos, ha de darse más peso a lo social que a lo político, sin por eso caer en que sea el individualismo la forma suprema de humanización. La dimensión social debe predominar sobre la dimensión política, aunque no sustiluirla.

Entre el individualismo y el estatismo dcbe construirse un tipo fuerte de sociedad, que supere el desenfreno de aquél y la imposición dominante de éste. No se trata de encontrar términos medios entre dos extremos ya existentes, sino de buscar formas nuevas, que, negándolos, superen los modelos existentes. Desde luego, la desestatización no debe entenderse como un reclamo neoliberal de un menor peso del Estado ante las exigencias de la llamada iniciativa privada y ante las leyes del mercado. La desestatización es, más bien, una socialización, que promueve una iniciativa comunitaria y social, no delegada ni en el Estado, ni en partidos, ni en vanguardias ni en caudillos. Se trata de superar la apatía social en la conducción de los procesos históricos sin tener que caer por eso en gremialismos o corporativismos. Lo que en el fondo se pretende con esto es, 
positivamente, dar más vida y decisión a las instancias sociales y, negativamente, superar los dinamismos pertubadores del poder político. Buscar el bien comunitario desde la presión comunitaria y por medios comunitarios sin delegar esta fucrza en instancias políicas, que se autonomizan y nunca pueden representar adecuadamente lo social, sería la característica principal de esta socialización.

La instancia pública no tiene por qué confundirse con la instancia política, y la reserva de todo el ámbito de lo público al Estado y a los partidos políicos con menoscabo de las instancias sociales no tiene por qué ser aceptada pues en el fondo representa una estatización de la vida social. Lo social representa no un medio, sino una mediación entre lo individual y lo político, de modo que la esencial dimensión comunal del individuo se realiza primariamente no en la dimensión política del Estado, sino en la dimensión pública de lo social. En distintos momentos de la lucha política latinoamericana se ha dado un cierto desprecio de los partidos en beneficio de las organizaciones populares. Pero esta tendencia no ha dado todo de sí al pretender que éstas asuman el poder político estatal con lo cual han vuelto a caer en los males de la mediación polflica para propugnar sus intereses reales. Asimismo, la Iglesia ha abdicado con frecuencia de su carácter de instancia social para convertirse en apéndice del poder político desvirtuando así su misión y debilitando con ello su potencial hisbórico al servicio de las mayorías populares.

Por lo que toca al permanente problema de la libertad y de la igualdadjusticia, la cuestión no reside en dar la primacía al individuo sobre el Estado o a éste sobre aquél. La unidad libertad-justicia-igualdad se logra mejor en la mediación de lo social, que ni es estatal ni es individual. La mediación de lo social posibilita aquella libertad individual-personal que no es individualista al tiempo que posibilita la libertad política, esto es, la libertad de los individuos y de los grupos ante el poder del Estado. Quien genera condiciones reales para la libertad personal es, ante todo, la libertad social y, a su vez, no es tanto el individuo como la agrupación, la cual se constituye en la mejor garantía real y efectiva conta la dominación y opresión de las estructuras político-estatales.

Esto implica que en el ámbito real de lo social desaparezcan las desigualdades excesivas y conflictivas, sin caer por ello en igualdades mecánicas, que no responden a las distintas preferencias en los valores y a la diversidad de las contribuciones de los individuos y de los grupos al bienestar social. Una igualdad obligada no responde a la realidad ni es exigida por consideraciones éticas o religiosas. Lo que debe ser excluido, por lo pronto, es la actual diferencia insultante entre quienes despilfarran y quienes no tienen para subsistir, y esto, aun cuando no se diera relación causal o funcional entre la pobreza y la riqueza. Lo que sí es una obligación imperiosa es el que se asegure a todos la satisfacción de sus necesidades básicas, pero superado ese nivel han de respetarse las 
opciones particulares y el trabajo o rendimiento mayor, siempre que se respete la igualdad de oportunidades y se eviten los procesos conducentes a desigualdades llamativas y provocantes de conflictos.

Esos planteamientos serían los nomnales y razonables para posibiliar una libertad-justicia-igualdad adecuada. Pero el ideal utópico de Jesús va mucho más allá. Paradojicamente, el seguidor de Jesús busca ocupar el último lugar como la vía más segura para llegar al primero, de modo que en este lugar no se sea dominante sino servidor, no se busque el propio honor sino el de los demás. En general lo que propugna el mensaje de Jesús es sustituir los dinamismos reales de este mundo viejo, de esta tierra vieja por los dinamismos del reino como ideal utópico de la tierra nueva, constiluida como negación -muerte y resurrecciónde la vieja. Las tremendas reservas del Nuevo Testamento ante la riqueza, el poder y el honor mundanos y su proclamación decidida de la pobreza, el servicio y la humillación de la cruz, pueden y deben ser trasladas al ámbito de lo visible y de lo social. No representan sólo un ideal posible para el individuo, sino un modelo para la sociedad. Que las realizaciones de esto, por ejemplo en el caso de las órdenes religiosas, grupos sociales que acuerpan a los individuos sin dejarlos a merced de instituciones más globalizantes, no hayan sido del todo salisfactorias, no impide que sirvan de cuestionamiento sobre la necesidad de dar came histórica social a la invitación que hace Jesús a su seguimiento. Las insutuciones sociales, a diferencia de las políticas, pueden impregnarse de aquél espíritu, que parecería sólo reservado a los individuos, y asf lo han pretendido los grandes fundadores de las órdenes religiosas.

El nuevo orden político, que se dibuja proféticamente en el horizonte utópico, se fundamenta en el intento de superar los modelos políticos, que son resultado y, a la vez, respaldo del capitalismo liberal y del colectivismo marxista.

No se está proponiendo una "tercera vía" cristiana entre el liberalismo y el colectivismo en lo económico ni entre la democracia liberal y la democracia social en to político. Tal "tercera via" no existe, ni siquiera como solución ideal, en los últimos documentos de la Iglesia (ver Sollicitudo rei socialis, 41). En esta fase historica lo que pueden darse son distintas formas de una u otra via, tanto en lo económico como en lo político, unas mejores que otras en su aplicación a una determinada realidad. No sería difficil comprobar que algunas formas políticas socialistas son mucho mejores que algunas formas políticas capitalistas $y$, al revés, que algunas formas capitalistas lo son respecto de otras formas socialistas. Esta graduación no deja de ser interesante y se suele presentar como una apertura de un sistema al otro, lo cual en la práctica los aproxima, no obstante sus diferencias fundamentales. En particular son interesantes los esfuerzos recientes bastante generalizados para democratizar el socialismo, los cuales apenas tienen su correspondencia en una muy necesaria socialización de las democracias, quiza porque las más avanzadas ya lo habían hecho de algún modo. 
Este doble movimiento de apertura en cada uno de los sistemas pucde estar mostrando, no sólo la insufíciencia de cada uno de cllos, sino un posible salto hacia un sistema político nuevo hasta ahora apenas reconocible. Es uno de los pocos puntos donde podría apreciarse un dinarnismo positivo de la historia, que va contrarrestando el dinamismo ciego de las exigencias del capital, sometido a constantes correcciones por lo que pudiera llamarse el dinamismo de humanización-divinización. Signos como la apreciación cada vez más connalural de los derechos humanos, de una mayor apertura democrática, de una más efectiva solidaridad mundial, son, entre otros, manifestaciones de la lucha entre el bien y el mal, entre la cerrazón de los sistemas y la apertura de la humanidad. Son signos positivos y esperanzadores, que apenas pueden ocultar la pesantez y la inercia de sus opuestos, pero que, no obstante, apuntan posibilidades de cambio por una vía reformista.

Desde América Latina, sin embargo, se ha buscado una y otra vez y aun se sigue buscando un cambio revolucionario, más bien que un cambio reformista, para lo cual se ha buscado en ocasiones aprovechar el dinamismo subversivo de la fe cristiana, así como los sistemas dominantes han aprovechado los dinamismos conservadores de esa misma fe. La razón es obvia. Se de un grado tal de injusticia estructural, esto es, afectante de la estructura misma de la sociedad, que parece indispensable exigir un cambio rápido y profundo de las estructuras, esto es, una revolución. Por otro lado, el dinamismo imperante no lleva de hecho a un reformismo, el cual por acumulación pudiera convertirse a la larga en un cambio revolucionario, sino a una profundización y extensión de la injusticia estructural, y esto so capa de reformismo, de vía al desarrollo.

Desde este punto de vista puede afirmarse tanto desde la teoría como desde la constatación de la realidad histórica y, desde luego, desde el profetismo utópico, que es necesaria una revolución de los actuales dinamismos y estructuras, una revolución anticapitalista -anti el capitalismo que se da en los países subdesarrollados y oprimidos - y una revolución antiimperialista -anti lodo tipo de imperio exterior, que intenta imponer sus intereses. El problema no es, entonces, si se necesita o no una revolución, sino qué revolución se necesita y cóno debe llevarse a cabo.

La revolución que se necesita, la revolución necesaria, será aquella que pretenda la libertad desde y para la justicia y la justicia desde y para la libernad, la libertad desde la liberación y no meramente desde la liberalización, sea ésta económica o política, para superar así el "mal común" dominante y construir un "bien común," entendido éste en contraposición de aquél y procurado desde una opción preferencial por las mayorías populares.

La imposición dogmática de que la democracia liberal es el mejor camino para juntar libertad y justicia en cualquier tiempo y circunstancia no deja de ser una presunción, ocultadora muchas veces de intereses ocasionales y elitistas. 
Asimismo la imposición dogmática de las llamadas democracias sociales o populares como la mejor y única forma de juntar adecuadamente libertad y justicia no se compadece con algunas de las formas realcs como se ha venido dando. Habría que atenerse al principio más radical de que es la realidad, tal como es sentida por las mayorías populares, y no principios dogmáticos y ni siquiera modelos históricos, la que se impusiera como crilerio de selección en la línea de una auténtica aulodeterminación. Antes que los criterios formales de uno u otro tipo de democracia estú la medida real de un sistema de derechos humanos debidamente jerarquizado y cuantificado.

Desde esta perspectiva, en los países centroamericanos y en la mayor parte del tercer mundo la liberación social se presenta con mayor necesidad y urgencia que la liberación política, cosa que tal vez no sea el caso en otras situaciones del primer y del segundo mundo. Desde luego no son excluyentes entre sí y, menos aún, contradictorias, pero la liberación social, con su soporte de satisfacción de las necesidades básicas de las mayorlas y su apoyo al ejercicio autónomo de la vida social, está por encima de la libertad política, que pretende igualdad de oportunidades para alcanzar el poder político y de las que llaman libertades estrictamente políticas como distintas de las libertades fundamentales. Y es que las libertades políticas para poder ser usufructuadas mayoritariamente necesitan de la liberación de las necesidades básicas y de la liberlad social, aunque éstas exijan a su vez ámbitos de liberlad política.

Áparece con ello una mayor connaturalidad, en la etapa actual de realización del reino en situaciones donde la mayor parte de la población vive en extrema pobreza y opresión, del ideal socialista que del ideal capitalisla con la inspiración profunda del mensaje cristiano, aunque ninguno de ellos se identifique con el ideal utópico cristiano. Otra cosa distinta es la posibilidad de realización real de cada uno de esos dos ideales.

Ya se han hecho muchas pruebas e intentos de corrección cristiana del capitalismo y los resultados no han sido buenos ni siquiera en el orden de la salisfacción de las necesidades básicas, ya no se diga en el terreno ético de construir un hombre nuevo y una tierra nueva, más conformes a los ideales utópicos del reino. Aunque en la enser̃anza social de la Iglesia se han formulado correcciones interesantes del capicalismo, se ha cometido con frecuencia el error de pensar que el capilalismo es fundamentalmente bueno y es el sistema más conforme con los valores cristianos. Por otro lado, el influjo de la fe cristiana y aun de las formas históricas de cristiandad en la corrección del capilalismo, tal como éste se ha dado en América Latina, donde la fe oficial ha sido la cristiana desde los tiempos de la conquista, sin ser del todo inoperante, muestra debilidades notables, que más han mundanizado —capitalizado- a la Iglesia que cristianizado - evangelizado- a las estructuras y comportanientos mundanos. 
Está mucho menos probado el intento de hacer de la fe cristiana fermento y levadura de los planteamientos marxistas. Algo ya se ha hecho en este sentido y así ha sido reconocido por los revolucionarios latinoamericanos desde Fidel Castro a los dirigentes sandinistas y del FMLN salvadoreño. La teología de la liberación ha pretendido desde distintas formas traer correcciones importantes al marxismo como la enseñanza social de la Iglesia habia pretendido lograrlo hasta hace no mucho con el capitalismo. No es que la teología de la liberación pretenda que la Iglesia haga dejación de su función social y polílica en manos de movimientos, partidos o vanguardias que la representen; al contratrio, exige un compromiso directo y autónomo de la Iglesia en la defensa de los derechos humanos y en la promoción de una mayor justicia y liberlad especialmente para los más necesilados. Pero sí pretende que las formas marxistas de revolución se transformen profundamente -y no sólo los hombres que las llevan a cabo-, porque en su teoría y, sobre todo, en su práctica, propenden a reduccionismos y a efectivismos poco concordes con el ideal utópico cristiano. A su vez la experiencia de lo mejor del marxismo le ha servido a la Iglesia de acicate y la ha obligado a volverse - a convertirse - hacia puntos radicales del mensaje cristiano, que el paso de los afios y la inculturación en formas capitalistas habían dejado meramente rilualizados e ideologizados sin peso histórico en los individuos y en los pueblos.

El nuevo orden cultural debiera desembarazarse de los modelos de cultura occidentales, pues éstos dejan mucho que desear a la hora de conseguir el perfeccionamiento del hombre y la felicidad de los humanos. Sólo despojándose y liberándose del engaño de que la cultura occidental ha encontrado ya, al menos la vía, del verdadero progreso humano, puede empezarse a buscar otro tipo de cultura.

El orden cultural consumista es un producto del orden económico consumista, por lo cual no es el adecuado para poner en marcha una civilización de la pobreza, la cual debe tener su correspondiente desarrollo cultural. No es por el camino del cambio permanente de entretenimientos como se va a engrandecer el acervo culural. Confundir el ser feliz con el estar entretenido, favorece y promueve el producto consumista a través de unas necesidades inducidas por la vía del mercadeo, pero, al mismo tiempo, descubre y fomenta el mayor de los vacios interiores. La civilización de la pobreza, lejos de ser en lo cultural consumista y activista, tiende a ser naturalista y a potenciar las actitudes contemplativas y comunicativas más que las activo-consumistas en unos casos y puramente pasivo-receptivas en otros.

La enorme riqueza cultural amasada por miles de años de vida hurnana, diferenciada en múltiples formas en distintos tiempos y lugares, no puede permitirse que reste anegada por las modas culturales, que buscan en lo nuevo la 
afirmación y consolidación de hombres que no son nuevos y que sólo pretenden vender novedad. Es necesario recuperar esa riqueza secular, no para quedarse consevadoramente en ella, pero sí para potenciarse hacia novedades no sustitutivas, sino superadoras. Muchos de los modelos tecnológicos y consumistas están perdiendo de vista y de uso, cuando no matando, la realidad y el profundo sentido de los grandes logros culturales, nacidos de una verdadera identidad cultural. Es desde la propia identidad, desde donde pueden asimilarse valores de otras culturas sin perderse en ellas. El caso, por ejemplo, de la asimilación inculturada de la fe cristiana hecha por el movimiento de la teología de la liberación es una buena muestra de cómo se puede hislorizar y particularizar, al mismo tiempo que enriquecer, una realidad universalizable.

La cultura debe ser, ante todo, liberadora. Liberadora de ignorancias, de temores, de presiones internas y externas, en busca de una apropiación de una verdad cada vez más plena y de una realidad cada vez más plenificante. En este proceso de liberación, la cultura irá siendo generadora de libertad real, no reducida a seleccionar -más que elegir-entre distintas ofertas condicionadas y condicionantes, sino orientada a la construcción del ser propio como personas, como comunidades, como pueblos y como naciones en un esfuerzo de creación y no sólo de aceptación. Hay en todo el mundo una tremenda imposición cultural, que universaliza desde centros poderosos la visión y la valoración del mundo con los más distintos medios comunicativos. Esta imposición cultural mantiene a las grandes mayorías de América Latina y de otras partes en formas alienadas de entenderse a sí mismas y de entender y valorar el mundo. Lo que debiera ser favorecedor de una unidad plural se convirte en uniformidad empobrecedora. La facilidad de los medios de comunicación, por otra parte, lleva a saltar alienadamente desde un estado primitivo, a veces muy rico y sano, de cultura a estadios solisticados y decadentes de una cultura impuesta más por el medio y envoltorio con que se presenta que por el fondo en que consiste.

AquI también el planteamiento es el de buscar una cultura para la mayorla y no una cultura elitista con mucha forma y poca vida. El que tengan vida y la tengan en abundancia no unos pocos, sino a ser posible todos, deberfa ser el lema de la nueva cultura en la tierra nueva. Tarea realmente utópica pero a la que impulsa - y el impulso se ve en muchas partes - el profetismo real, que repudia y supera las lacras de una cultura alienante y, en el fondo, deshumanizante.

La creación de un nuevo cielo supone lograr una nueva presencia de Dios entre los hombres, lo cual permitiría transformar la vieja Babilonia en la nueva Jerusalén.

Ciertamente todo lo anterior, expresado bajo las rúbricas del hombre nuevo y de la tierra nueva, es una muy especial presencia del Espíitu de Cristo en el mundo, enviado por el Crucificado y Resucitado. Pero requiere una explicitación y visibilización mayor, que es la expresada en el nuevo cielo, no como algo 
superpuesto al hombre y a la tierra, sino como algo integrado y estructurado con ellos.

Así, por "nuevo cielo" se debe entender aquí aquella presencia de Dios en la nueva tierra," que va posibilitando y animando el que Dios sea todo en todos y en wodo $(1$ Cor 15, 28), porque Cristo lo es todo para lodos (Col 3,11). Es, por tanlo, un nuevo cielo cristológico y no simplemente el cielo de un Dios abstracto. unívoco en su abstracción. No se trata, tampoco, del cielo como lugar final de los resucilados en gracia, sino del cielo presente en la historia, de la presencia histórica y cada vez más operante y visible de Dios entre los hombres y las estructuras humanas públicas. El Jesús histórico ha de constituirse, no solo en Cristo de la fe, sino también en Cristo histórico, eslo es, en la historización visible y elicaz de la afirmación paulina de que El sea todo en lodos y para todo, de que la vida real de hombres e instituciones - con la diferencia esencial que esa vida debe tomar en unos y en otras - no sea ya la vida surgida de sus limitados y pecaminosos principios inmanentes, sino la vida surgida de los principios que hacen nuevas todas las cosas, que crean, regeneran y transforman lo que hay de insuficiente y aun de pecaminoso en la criatura vieja.

Vistas así las cosas, el nuevo cielo desborda lo que se entiende habitualmente por Iglesia, aunque no lo que se debiera entender por la ciudad de Dios y, desde luego, por reino de Dios. No obstante la referencia a la Iglesia es imprescindible a la hora de describir adecuadamente el cielo nuevo, bajo y en el cual vivir históricamente, mientras la historia de Dios sigue en peregrinación o Dios sigue peregrinando por la historia como Cristo histórico.

Efectivamente, una de las formas principales, como deberia historizarse este nuevo cielo es la Iglesia de Cristo como cuerpo histórico de Jesús crucificado y resucitado.

No basta con afirmar que la Iglesia hace presente la vida divina, transmilida sacramentalmente. Esto es importante, pero no es suficiente. Por lo pronto, esa presencia sacramental de la Iglesia como un bodo y de los distintos sacramentos, en que esa sacramentalidad fundamental se actualiza (Rahner), debiera revitalizarse más allá de lo rilual y formal hasta recuperar la efectividad de la Palabra y la correspondencia activa de quien recibe la gracia del sacramento. Confundir el misterio, que es el sacramento, con un proceso dado en la interioridad de la persona es devaluar la misteriosidad de la eficacia en una pura alirmación inverificable e inoperante. Aun desde este punto de vista es indispensable, profética y utópicamente, una profunda renovación, sin la cual no es pensable revitalizar la vida sacramental.

Pero la Iglesia debe ir más allá del ámbito sacramental o, al menos, su sacramentidad debe ser entendida más ampliamente; para ello necesita estar permanentemente abierta y atenta a la novedad y a la universalidad del Espíritu, 
que rompe la rulina esclerotizada del pasado y los límites de una autoconcepción restringida. Sólo una Iglesia que se deja invadir por el Espíritu renovador de todas las cosas y que está atenta a los signos de los tiempos puede convertirse en el cielo nuevo, que necesitan el hombre y la tierra nuevos.

La Iglesia, como institución, propende a ser conservadora del pasado más que renovadora del presente y creadora de futuro. Ciertamente hay cosas que conservar, pero nada vital y humano, nada histórico se conserva si no se mantiene en permanente renovación. El miedo a lo nuevo, a lo no controlable por los medios institucionales ya establecidos, ha sido y sigue siendo una de las características permanentes de la Iglesia. Cuando se recogen las posiciones de las distintas autoridades eclesiásticas frente a los movimientos religiosos renovadores, que después han mostrado ser fundamentales para la marcha de la Iglesia (por ejemplo, las fundaciones de las grandes ordenes religiosas, las nuevas formas de pensamiento, los nuevos métodos y aun los datos de la investigación bíblica, etc.) y ya no se diga frente a los avances científicos y políticos, es difícil sostencr que la autoridad de la Iglesia y sus órganos institucionales han estado abierlos a la novedad de la historia y al soplo creador del Espíritu.

Es, sin embargo, absolutamente indispensable esta apertura al Espíritu de Cristo desde la terrenalidad, que implica el seguimiento del Jesús histórico. No hay instancia eclesiástica, que sustituya esta necesidad, pues el Espíritu de Cristo no ha delegado la totalidad de su presencia y de su eficacia en ninguna de las instancias instilucionales, aunque la corporeidad historica de éstas sea también una exigencia del Espíritu. Lo que sucede con frecuencia es que esta instutucionalidad se configura más desde la ley que desde la gracia, como si la institucionalidad eclesial debiera configurarse más según leyes sociológicas y políticas de indole tolalitaria, disfrazada de volunlad de Dios y su correspondiente obediencia que según el dictado y la fuerza del Esplritu. Por otro lado, no se trata de un Espíritu cualquiera, inventado por cualquier carismático, sino del Espíritu de Jesús, el que animó su concepción, se hizo presente en su bautismo, se hizo presente en toda su persona y vida y que funalmente prometió enviar, cuando él faltara.

Es en este contexto donde se hacen presentes los signos de los tiempos, unos en determinada época y otros en otra, unos en determinadas regiones del mundo y otros en otra. Son precisamente los signos de los tiempos, los que aportan el elemento de futuro y sin los cuales se carece de un elemento esencial para la interpretración de la palabra de Dios y de una de las mayores fuerzas de renovación. Pero unos signos de los tiempos enmarcados en la dialéctica utopiaprofecía, sin la cual se volvería a caer en el idealismo ineficaz.

Desde la siluación actual de América Launa, la renovación de la Iglesia y su proyección hacia el futuro, si es que ha de convertirse en el cielo nuevo, ha de ser 
superpuesto al hombre y a la tierra, sino como algo integrado y estructurado con ellos.

Así, por "nuevo cielo" se debe entender aquí aquella presencia de Dios en la nueva tierra," que va posibilitando y animando el que Dios sea todo en lodos y en todo (1Cor 15, 28), porque Cristo lo es todo para todos (Col 3,11). Es, por tanto, un nuevo cielo cristológico y no simplemente el cielo de un Dios abstracto, univoco en su abstracción. No se trala, tampoco, del cielo como lugar final de los resucitados en gracia, sino del cielo presente en la historia, de la presencia histórica y cada vez más operante y visible de Dios entre los hombres y las estrucluras humanas públicas. El Jesús histórico ha de constituirse, no solo en Cristo de la fe, sino también en Cristo histórico, esto es, en la historización visible y eficaz de la alirmación paulina de que El sea todo en todos y para todo, de que la vida real de hombres e instituciones - con la diferencia esencial que esa vida debe tomar en unos y en otras - no sea ya la vida surgida de sus limitados y pecaminosos principios inmanentes, sino la vida surgida de los principios que hacen nuevas todas las cosas, que crean, regeneran y transforman lo que hay de insuficiente y aun de pecaminoso en la criatura vieja.

Vistas así las cosas, el nuevo ciclo desborda lo que se entiende habilualmente por Iglesia, aunque no lo que se debiera entender por la ciudad de Dios y, desde luego, por reino de Dios. No obstante la referencia a la Iglesia es imprescindible a la hora de describir adecuadamente el cielo nuevo, bajo y en el cual vivir históricamente, mientras la historia de Dios sigue en peregrinación o Dios sigue peregrinando por la historia como Cristo histórico.

Efectivamentc, una de las formas principales, como debería historizarse este nuevo cielo es la Iglesia de Cristo como cuerpo histórico de Jesús crucificado y resucitado.

No basta con afirmar que la Iglesia hace presente la vida divina, transmitida sacramentalmente. Esto es importante, pero no es suficiente. Por lo pronto, esa presencia sacramental de la Iglesia como un todo y de los distintos sacramentos, en que esa sacramentalidad fundamental se actualiza (Rahner), debiera revitalizarse más allá de lo ritual y formal hasta recuperar la efectividad de la Palabra y la correspondencia activa de quien recibe la gracia del sacramento. Confundir el misterio, que es el sacramento, con un proceso dado en la interioridad de la persona es devaluar la misteriosidad de la eficacia en una pura afirmación inverificable e inoperante. Aun desde este punto de vista es indispensable, profética y utópicamente, una profunda renovación, sin la cual no es pensable revilalizar la vida sacramental.

Pero la Iglesia debe ir más allá del ámbito sacramental o, al menos, su sacramentidad debe ser entendida más ampliamente; para ello necesila estar permanentemente abierta y atenta a la novedad y a la universalidad del Espíritu, 
que rompe la rulina esclerolizada del pasado y los límites de una auloconcepción restringida. Sólo una Iglesia que se deja invadir por el Espíritu renovador de todas las cosas y que está atenta a los signos de los tiempos puede convertirse en el cielo nuevo, que necesilan el hombre y la tierra nuevos.

La Iglesia, como institución, propende a ser conservadora del pasado más que renovadora del presente y creadora de futuro. Cierlamente hay cosas que conservar, pero nada vital y humano, nada histórico se conserva si no se mantiene en permanente renovación. El miedo a lo nuevo, a lo no controlable por los medios institucionales ya establecidos, ha sido y sigue siendo una de las características permanentes de la Iglesia. Cuando se recogen las posiciones de las distintas autoridades eclesíśsicas frente a los movimientos religiosos renovadores, que después han mostrado ser fundamentales para la marcha de la Iglesia (por ejemplo, las fundaciones de las grandes ordenes religiosas, las nuevas formas de pensamiento, los nuevos métodos y aun los datos de la investigación bíblica, ele.) y ya no se diga frente a los avances científicos y políticos, es difícil sostener que la autoridad de la Iglesia y sus órganos institucionales han estado abiertos a la novedad de la historia y al soplo creador del Espíritu.

Es, sin embargo, absolutamente indispensable esta apertura al Espíritu de Cristo desde la terrenalidad, que implica el seguimiento del Jesús historico. No hay instancia eclesiástica, que sustituya esta necesidad, pues el Espíritu de Cristo no ha delegado la totalidad de su presencia y de su eficacia en ninguna de las instancias institucionales, aunque la corporeidad histórica de éstas sea también una exigencia del Espíritu. Lo que sucede con frecuencia es que esta institucionalidad se configura más desde la ley que desde la gracia, como si la institucionalidad eclesial debiera configurarse más según leyes sociológicas y políticas de indole totalitaria, disfrazada de voluntad de Dios y su correspondiente obcdiencia que según el dictado y la fuerza del Espíritu. Por otro lado, no se trata de un Espíritu cualquiera, inventado por cualquier carismático, sino del Espíritu de Jesús, el que animó su concepción, se hizo presente en su bautismo, se hizo presente en toda su persona y vida y que finalmente prometio enviar, cuando él falıara.

Es en este contexto donde se hacen presentes los signos de los tiempos, unos en determinada época y otros en otra, unos en determinadas regiones del mundo y otros en otra. Son precisamente los signos de los tiempos, los que aportan el elemento de futuro y sin los cuales se carece de un elemento esencial para la interpretración de la palabra de Dios y de una de las mayores fuerzas de renovación. Pero unos signos de los tiempos enmarcados en la dialéclica utopíaprolecía, sin la cual se volvería a caer en el idealismo ineficaz.

Desde la siluación actual de América Latina, la renovación de la Iglesia y su proyección hacia el futuro, si es que ha de convertirse en el cielo nuevo, ha de ser 
en la línea de la Iglesia de los pobres. Una Iglesia que haya hecho efectivamente una opción preferencial por los pobres será, por un lado, prueba y manifestación del Espíitu renovador presente en ella y, por ouro, garantía de que pueda convertirse en cl cielo nuevo de la tierra y del hombre nuevos. El ejercicio utópico de la profecía puede llevar a una Iglesia, configurada en gran parte por los dinamismos del capitalismo occidental como una Iglesia de los ricos y de los poderosos, que en el mejor de los casos deriva hacia los más pobres las migajas desprendidas de la abundancia, a irse convirtiendo - en verdadera "conversión"- en una Iglesia de los pobres, que realmente pueda ser el cielo de una lierra en la cual vaya dominando una civilización de la pobreza y en la cual los hombres sean no sólo intencional y espiritualmente pobres, sino que lo sean real y materialmente, esto es, despegados de lo superfluo y de los dinamismos constringentes del acaparamiento individual y de la acumulación colectiva. El dinero puede ser para los hombres y para los estados un incentivo, para el desarrollo material, pero ha sido sicmpre y sigue siéndolo cada vez más un veneno letal para un auténtico humanismo y, desde luego, para un auténtico cristianismo. Que esto suscile un poderoso rechazo mundano, que esto sea un escándalo y aun un insulto para la civilización de la riqueza, es una prueba más de la continuidad de estas ideas y de esta práctica con la línea evangélica más plena, sicmpre atacada con los mismos reproches.

Es en este sentido como la Iglesia de los pobres se constituye en el nuevo cielo, que como bal se necesila para superar la civilización de la riqueza y construir la civilización de la pobreza, nueva tierra, en la que habite, como en un hogar acogedor y no degradado cl hombre nuevo. Aquí es donde se da una gran confluencia del mensaje cristiano sin glosas desfigurantes con la situación actual de la mayor parte del mundo y, ciertamente, de América Latina, aún depositaria mayoritariamente de la fe cristiana, la cual, sin embargo, hasta ahora poco ha servido para hacer de esta región una tierra nueva, no obstante haberse presentado inicialmente como el nuevo mundo. La negación profética de una Iglesia como el cielo vicjo de una civilización de la riqueza y del imperio y la afirmación utópica de una Iglesia como el cielo nuevo de una civilización de la pobreza es un reclamo irrecusable de los signos de los tiempos y de la dinámica soteriológica de la fe cristiana historizada en hombres nuevos, que siguen anunciando firmemente, aunque siempre a oscuras, un futuro sicmpre mayor, porque más allá de los sucesivos futuros históricos se avizora el Dios salvador, el Dios liberador. 